
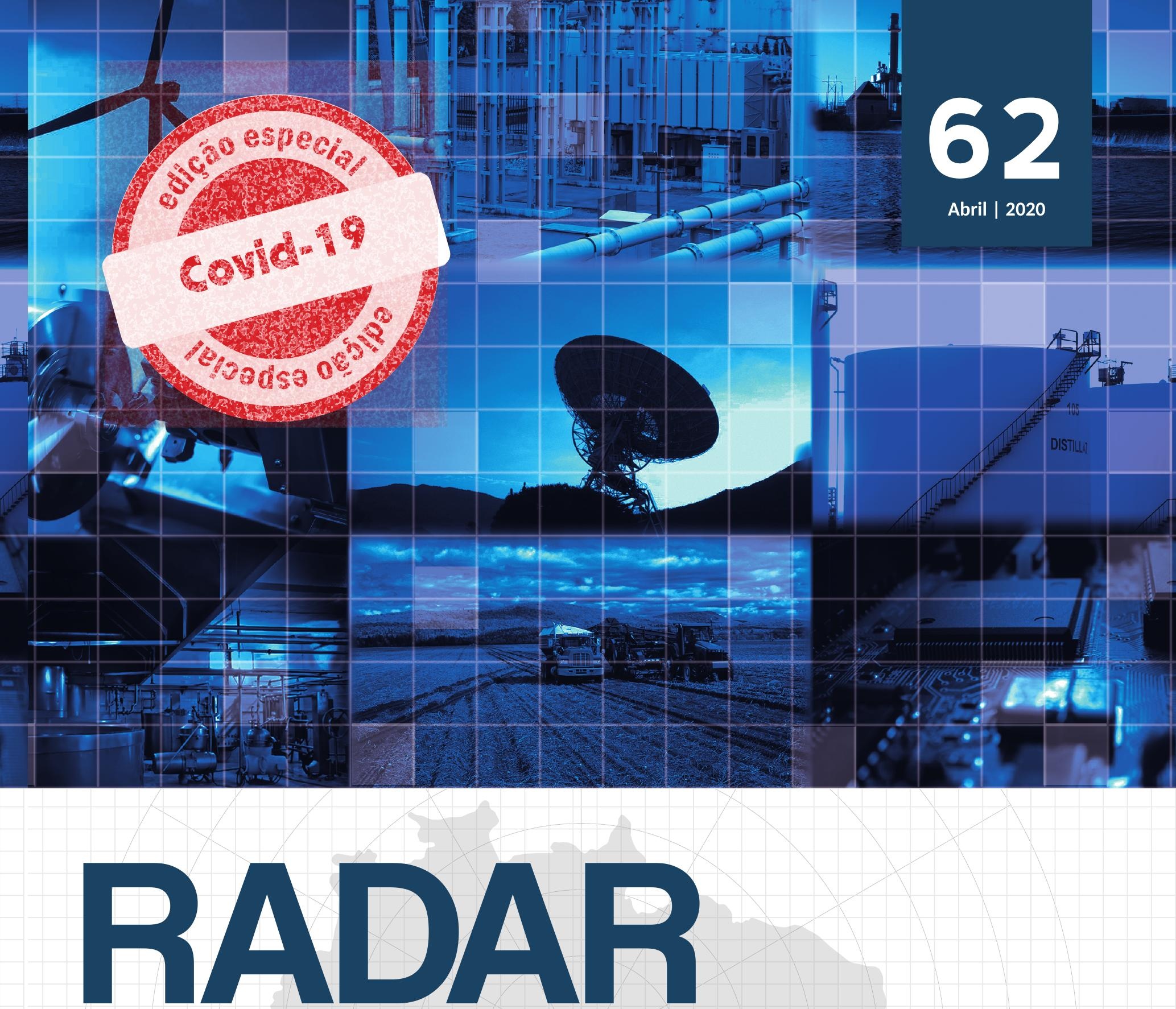

Tecnologia, Produção e Comércio Exterior

\title{
ipea
}

Diretoria de Estudos e Políticas Setoriais de Inovação e Infraestrutura 



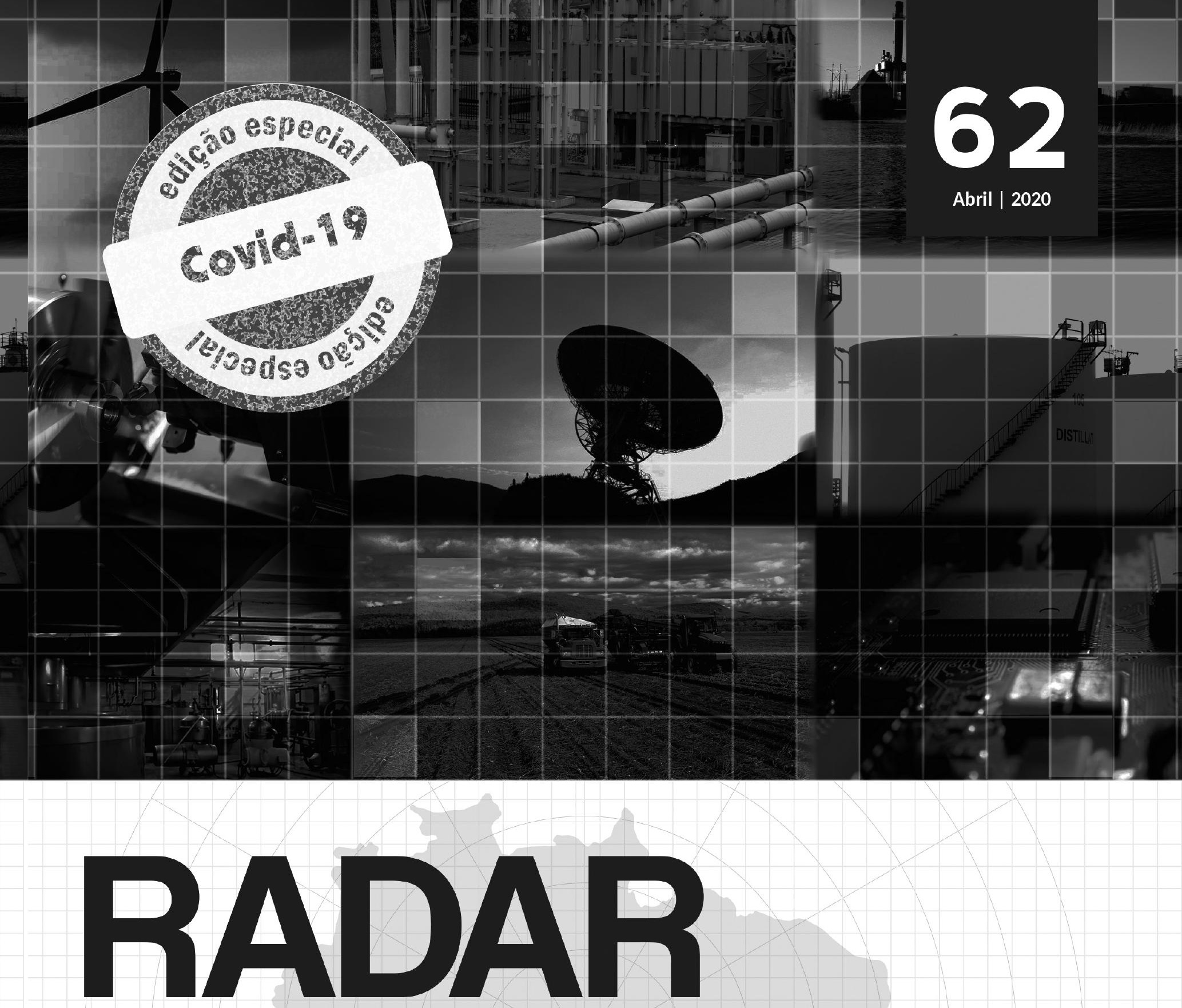

\section{Tecnologia, Produção e Comércio Exterior}

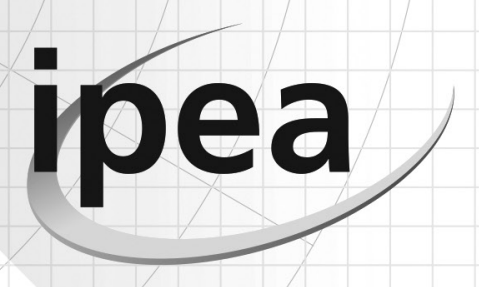

Diretoria de Estudos e Políticas Setoriais de Inovação e Infraestrutura 


\section{Governo Federal \\ Ministério da Economia \\ Ministro Paulo Guedes}

\section{ipea}

Fundação pública vinculada ao Ministério da Economia, o Ipea fornece suporte técnico e institucional às ações governamentais - possibilitando a formulação de inúmeras políticas públicas e programas de desenvolvimento brasileiros - e disponibiliza, para a sociedade, pesquisas e estudos realizados por seus técnicos.

\section{Presidente}

Carlos von Doellinger

\section{Diretor de Desenvolvimento Institucional}

Manoel Rodrigues Junior

Diretora de Estudos e Políticas do Estado, das Instituições e da Democracia

Flávia de Holanda Schmidt

\section{Diretor de Estudos e Políticas}

Macroeconômicas

José Ronaldo de Castro Souza Júnior

Diretor de Estudos e Políticas Regionais, Urbanas e Ambientais

Nilo Luiz Saccaro Júnior

Diretor de Estudos e Políticas Setoriais de Inovação e Infraestrutura

André Tortato Rauen

\section{Diretora de Estudos e Políticas Sociais}

Lenita Maria Turchi

Diretor de Estudos e Relações Econômicas

e Políticas Internacionais

Ivan Tiago Machado Oliveira

\author{
Assessora-chefe de Imprensa \\ e Comunicação \\ Mylena Fiori
}

Ouvidoria: http://www.ipea.gov.br/ouvidoria

URL: http://www.ipea.gov.br

\section{RADAR}

\section{Tecnologia, produção e comércio exterior}

\author{
Editor responsável \\ Rafael Leão
}

Radar : tecnologia, produção e comércio exterior / Instituto de Pesquisa Econômica Aplicada. Diretoria de Estudos e Políticas Setoriais de Inovação e Infraestrutura (Diset). - n. 1 (abr. 2009) - - Brasília : Ipea, 2009-

Quadrimestral

ISSN: 2177-1855

1. Tecnologia. 2. Produção. 3. Comércio Exterior. 4. Periódicos. I. Instituto de Pesquisa Econômica Aplicada. Diretoria de Estudos e Políticas Setoriais de Inovação e Infraestrutura (Diset).

CDD 338.005

(C) Instituto de Pesquisa Econômica Aplicada - ipea 2020

As publicações do Ipea estão disponíveis para download gratuito nos formatos PDF (todas) e EPUB (livros e periódicos).

Acesse: http://www.ipea.gov.br/portal/publicacoes

As opiniões emitidas nesta publicação são de exclusiva e inteira responsabilidade dos autores, não exprimindo, necessariamente, o ponto de vista do Instituto de Pesquisa Econômica Aplicada ou do Ministério da Economia.

É permitida a reprodução deste texto e dos dados nele contidos, desde que citada a fonte. Reproduções para fins comerciais são proibidas. 


\section{SUMÁRIO}

AÇÕES GOVERNAMENTAIS PARA ACELERAR A PESQUISA CIENTÍFICA E A INOVAÇÃO FRENTE À PANDEMIA

Fernanda De Negri

Graziela Zucoloto

Pedro Miranda

Priscila Koeller

COORDENAÇÃO GOVERNAMENTAL NA CRISE

DA COVID-19: BREVE PROPOSTA DE AÇÃO

Flávia Schmidt

Janine Mello

Pedro Cavalcante

EMPREGO SETORIAL E O ENFRENTAMENTO À COVID-19

André Rauen

Bianca Paiva

Rafael Leão

Bernardo Furtado

POLÍTICAS DE DESENVOLVIMENTO PRODUTIVO TECNOLÓGICO E DE INOVAÇÃO: A PERSPECTIVA DA SEGURANÇA NACIONAL

Rafael Leão

Luis Felipe Giesteira

RESENHA DAS NOTAS TÉCNICAS EVITANDOA PANDEMIA DA POBREZA: POSSIBILIDADES PARA O PROGRAMA BOLSA FAMILILIA E PARA O CADASTRO ÚNICO EM RESPOSTAÀ COVID-19 E ESTIMATIVAS DE PÚBLICO ELEGÍVEL E CUSTOS DO BENEFÍCIO EMERGENCIAL CRIADO PELO PL № 9.236/2017

Rafael Leão 



\section{APRESENTAÇÃO}

A pandemia da Covid-19 levou o Ipea a produzir uma série de trabalhos, em caráter emergencial, sobre as possíveis açôes que o Estado brasileiro poderia adotar para combater os efeitos sanitários, econômicos e sociais desta crise. Como o debate público no país tornou-se monotemático, com todas as atençôes voltadas à Covid-19, decidiuse elaborar uma edição especial do boletim Radar para a compilação de alguns desses trabalhos. Esta edição especial (n⿳0 62) traz cinco trabalhos, sendo dois deles inéditos; outros dois são versôes adaptadas de trabalhos já previamente publicadas para o foco desta edição; o último texto é uma resenha com os principais resultados de duas notas técnicas sobre o mesmo tema.

Esta edição inicia-se com o texto Açôes governamentais para acelerar a pesquisa científica e a inovação frente à pandemia, elaborado por Fernanda De Negri, Graziela Zucoloto, Pedro Miranda e Priscila Koeller. Os autores mostram que o Brasil, a despeito da fragilidade de sua estrutura de pesquisa e da redução recente dos investimentos em ciência e tecnologia (C\&T), ainda vem se mostrando capaz de contribuir com os esforços globais na busca por tratamentos e pela cura da Covid-19.

Em seguida, o artigo Coordenação governamental na crise da Covid-19: breve proposta de ação apresenta concretas sugestôes de arranjo institucional de coordenação governamental que podem contribuir para um melhor desempenho das açóes adotadas pelo governo brasileiro neste momento de crise. Os autores do texto, Flávia Schmidt, Janine Mello e Pedro Cavalcante, apresentam uma discussão sobre a ação coordenada do Estado em todas as dimensóes pertinentes à crise.

O terceiro estudo, Emprego setorial e o enfrentamento à Covid-19, propóe um indicador de identificação de atividades econômicas prioritárias para eventual apoio público governamental diante da atual pandemia da Covid-19. Os autores, André Rauen, Bianca Paiva, Rafael Leão e Bernardo Furtado, realizam um exercício empírico para fornecer alguma orientação, com foco setorial, à ação emergencial do Estado.

Por seu turno, o artigo Políticas de desenvolvimento produtivo, tecnológico e de inovação: a perspectiva da segurança nacional, de autoria de Rafael Leão e Luis Felipe Giesteira, resgata o debate sobre essas políticas públicas como instrumentos de segurança nacional e estabilidade institucional. Os autores sugerem que a construção de capacidade produtiva, tecnológica e de inovação, com base em missóes e demandas de Estado, dotaria o país de condiçôes para responder mais efetivamente a outras crises.

Finalmente, a Resenha das notas técnicas Evitando a pandemia da pobreza: possibilidades para o Programa Bolsa Familia e para o Cadastro Único em Resposta à Covid-19 e Estimativas de público elegivel e custos do benefício emergencial criado pelo PL nº 9.236/2017 consolida as principais recomendaçôes e análises de açóes emergenciais para as populações mais vulneráveis, formuladas por Luís Henrique Paiva, Pedro H. G. Ferreira de Souza, Letícia Bartholo e Sergei Soares nas duas notas técnicas citadas.

Rafael Leão

Especialista em políticas públicas e gestão governamental na Diretoria de Estudos e Políticas Setoriais de Inovação e Infraestrutura (Diset) do Ipea e editor deste Radar 



\title{
AÇÕES GOVERNAMENTAIS PARA ACELERAR A PESQUISA CIENTÍFICA E A INOVAÇÃO FRENTE À PANDEMIA ${ }^{1}$
}

\author{
Fernanda De Negri² \\ Graziela Zucoloto 3 \\ Pedro Miranda ${ }^{4}$ \\ Priscila Koeller ${ }^{5}$
}

\section{SINOPSE}

A pandemia de coronavírus (Covid-19) terá impactos significativos sobre a sociedade. Nesse momento, a produção científica é crucial para melhor compreender a doença e seus efeitos e buscar soluçôes, e seu enfrentamento requer a opinião especializada de cientistas e pesquisadores e a coordenação governamental, para ampliar pesquisas na área para entender e se preparar para o que está por vir. O Brasil, a despeito da fragilidade de sua estrutura de pesquisa e da redução recente dos investimentos em ciência e tecnologia (C\&T), ainda vem se mostrando capaz de contribuir em momento tão grave quanto o atual.

Palavras-chave: pandemia; coronavírus; Covid-19; pesquisa científica; ação governamental.

\section{INTRODUÇÃO}

A pandemia de coronavírus (Covid-19) terá impactos significativos e ainda não completamente dimensionados sobre a sociedade. Trata-se de um evento inédito na história, dado que, no passado, epidemias parecidas se desenvolveram em um cenário de muito menor integração entre países e pessoas, divisão do trabalho e densidade populacional. Até dia 25 de março, o mundo contabilizava aproximadamente 413 mil casos e 18,4 mil mortes: ${ }^{6}$ uma letalidade de aproximadamente 4\%. Entretanto, esse número não é inteiramente preciso, pois varia significativamente com o número de pessoas testadas, já que pessoas com sintomas leves não têm sido testadas na maioria dos países.

Por se tratar de uma doença e de uma situação novas, as lacunas de informação e conhecimento ainda são muito grandes: taxas de letalidade, potencial de transmissão, tratamento, existência de outros efeitos ou sequelas no organismo dos que foram infectados; todas essas informaçóes ainda são preliminares.

Neste momento, a produção científica é crucial para melhor compreender a doença e seus efeitos e buscar soluções. Pesquisadores e cientistas, no mundo todo, em muitos casos a partir de uma boa coordenação governamental, estão se mobilizando para estimar tanto os efeitos da doença sobre a saúde da população quanto os impactos econômicos e sociais dessa pandemia. A Organização Mundial da Saúde (OMS), ${ }^{7}$ por exemplo,

\footnotetext{
1. Uma versão mais completa deste trabalho está disponível em: $<$ https://bit.ly/3bcswli>.

2. Técnica de planejamento e pesquisa na Diretoria de Estudos e Políticas Setoriais de Inovação e Infraestrutura (Diset) do Ipea.

3. Técnica de planejamento e pesquisa na Diset/lpea.

4. Técnico de planejamento e pesquisa na Diset/lpea.

5. Técnica de planejamento e pesquisa na Diset/lpea.

6. Informações da OMS disponíveis em: <https://bit.ly/3bfcJs9>. Dados interessantes sobre a epidemia no mundo também podem ser obtidos nos links: $<$ https://www.worldometers.info/coronavirus/> e <https://coronavirus.jhu.edu/map.html>.

7. Disponivel em: <https://www.who.int/blueprint/priority-diseases/key-action/novel-coronavirus/en/>.
} 
tem coordenado e mapeado os esforços de pesquisa no mundo, reunindo cientistas no tema e identificando as prioridades de pesquisa ${ }^{8}$ neste momento. Portanto, este texto procura descrever alguns desses esforços de pesquisa, bem como detalhar informaçôes críticas para que esses esforços sejam bem-sucedidos.

\section{ALGUMAS AÇÕES ADOTADAS PELOS GOVERNOS ATÉ O MOMENTO}

Em um cenário de emergência de saúde pública internacional, as açôes adotadas pelos governos para acelerar pesquisas na área têm fundamental importância. Diversos países do mundo têm procurado coordenar suas iniciativas de pesquisa internamente e articular os esforços àqueles identificados pela OMS. Inúmeros editais de pesquisa foram lançados nos últimos meses para fazer frente a este desafio, como sintetizado na quadro 1.

QUADRO 1

Editais de pesquisa

\begin{tabular}{|c|c|c|c|}
\hline País/bloco & Instituição com editais para P\&D & Valor & Coordenação com organismos internacionais ${ }^{1}$ \\
\hline \multirow{4}{*}{ Brasil } & Empresa Brasileira de Pesquisa e Inovação Industrial (Embrapii) & $\mathrm{R} \$ 6$ milhões & Não \\
\hline & $\begin{array}{l}\text { Fundação de Amparo à Pesquisa do Estado de S. Paulo } \\
\text { (Fapesp) }\end{array}$ & $\mathrm{R} \$ 10$ milhões & Não \\
\hline & Fapesp-Financiadora de Estudos e Projetos (Finep) & $\begin{array}{l}R \$ 20 \text { milhões ( } 50 \% \text { referente à } \\
\text { Finep e } 50 \% \text {, à Fapesp) }\end{array}$ & Não \\
\hline & Serviço Nacional de Aprendizagem Industrial (Senai) & $\mathrm{R} \$ 10$ milhões & Não \\
\hline \multirow{2}{*}{ União Europeia } & Comissão Europeia [1] & $€ 47,5$ milhões & OMS e ECDC \\
\hline & Comissão Europeia [2] & $€ 164$ milhões & Não \\
\hline \multirow{2}{*}{ Alemanha } & Fundação Alemã de Pesquisa (DFG) & Não disponível & Não \\
\hline & Rede Nacional de Pesquisa em Doenças Infecciosas Zoonóticas & $€ 10$ milhões & OMS \\
\hline \multirow[b]{2}{*}{ França } & Agência Nacional de Pesquisa da França (ANR) & $€ 3$ milhões & OMS \\
\hline & $\begin{array}{l}\text { REACTing (Pesquisa e ação voltada para doenças infecciosas } \\
\text { emergentes) }\end{array}$ & $€ 1$ milhão & não \\
\hline \multirow{2}{*}{ Estados Unidos } & Departamento de Energia (DOE) & Não disponível & Não \\
\hline & Institutos Nacionais de Saúde (NIH) & Não disponível & OMS \\
\hline Canadá & Institutos canadenses de pesquisa em saúde & CAD $\$ 52,6$ milhões & OMS e GloPID-R \\
\hline \multirow{2}{*}{ Reino Unido } & Conselho de Pesquisa Médica (MRC) & f 20 milhões & $\begin{array}{l}\text { OMS, GloPID-R, CEPI, Wellcome e Comissão } \\
\text { Europeia }\end{array}$ \\
\hline & Wellcome & f 10 milhões & $\begin{array}{l}\text { Departamento para Desenvolvimento Interna- } \\
\text { cional do Reino Unido (DFID-UK) }\end{array}$ \\
\hline
\end{tabular}

Obs.: Dados coletados em 25 de marco de 2020.

Nota: ${ }^{1}$ Concerne à menção explícita nos editais e/ou nas páginas (sites) das instituições a que se referem esses editais.

No Brasil, as iniciativas de coordenação pelo governo federal, em especial pelo Ministério da Ciência, Tecnologia, Inovaçóes e Comunicações (MCTIC), ainda estão se iniciando. Foi instituído no começo de março de 2020 o Comitê de Especialistas Rede Vírus do MCTIC, que pretende exatamente promover a integração

8. Foram identificadas as prioridades em nove áreas temáticas: vírus - história natural, transmissão e diagnóstico; pesquisas em animais e no ambiente de origem do vírus e medidas de manejo na interface homem-animal; estudos epidemiológicos; caracterização clínica e manejo; prevenção e controle de infecções, incluindo a proteção dos profissionais de saúde; candidato a terapias na P\&D; candidato a vacina na P\&D; considerações éticas para pesquisa; e ciências sociais na resposta ao surto (virus - natural history, transmission and diagnostics; animal and environmental research on the virus origin, and management measures at the human-animal interface; epidemiological studies; clinical characterization and management; infection prevention and control, including health care workers' protection; candidate therapeutics $R \& D$; candidate vaccines $R \& D$; ethical considerations for research; social sciences in the outbreak response). Disponivel em: <https://www.who.int/blueprint/priority-diseases/key-action/Global_Research_Forum_FINAL_VERSION_for_web_14_feb_2020.pdf?ua=1>. 
dos esforços de pesquisa científica e desenvolvimento; definir as prioridades de pesquisa; articular e integrar as iniciativas de pesquisa, desenvolvimento e inovação (PDI); e promover o desenvolvimento de tecnologias sobre viroses emergentes.

Como forma de promoção de esforços em PDI sobre o tema, foram lançados três editais que totalizam R \$ 40 milhóes, sendo dois deles voltados para empresas e pequenas empresas do estado de Sáo Paulo (respectivamente, Senai e Fapesp/Finep), e o outro voltado para instituiçóes científicas e tecnológicas da Fapesp. O edital do Senai é bastante abrangente - podendo participar projetos de consultoria, metrologia, ensaios, análises e/ou PDI - e foca no impacto de curto prazo, enquanto os demais definem como principais objetivos o desenvolvimento de kits de diagnóstico e respiradores mecânicos.

$\mathrm{Na}$ análise dos editais em andamento no país, e das informaçôes disponíveis nos sites das instituições, destaca-se o fato de não haver menção às prioridades estabelecidas pela Organização Mundial da Saúde, ou às iniciativas internacionais.

Um levantamento preliminar em países selecionados (Alemanha, França, Estados Unidos, Canadá e Reino Unido) aponta para uma outra realidade, estando a maior parte deles coordenados com as prioridades da OMS. Ademais, a maior parte dos países tem um órgão que centraliza, se não as demandas por pesquisas na área de saúde, as informaçóes relativas às pesquisas em desenvolvimento e aos editais disponíveis. Como exemplo do volume de recursos adicionais alocados à PDI, pode-se destacar o Reino Unido, com $\mathrm{f} 30$ milhóes, e o Canadá, com CAD\$ 52 milhóes.

Além da atuação dos Estados nacionais e da OMS, destacam-se ainda as iniciativas da União Europeia, coordenadas com as prioridades da OMS e do European Centre for Disease Prevention and Control, ${ }^{9}$ que lançou um edital específico voltado às pesquisas sobre o coronavírus, com recursos da ordem de €50 milhóes e do edital lançado para startups e pequenas e médias empresas, que conta com cerca de $€ 160$ milhóes. Somam-se a essas as iniciativas de coordenação internacional das pesquisas da Glopid-R, que reúne em nível internacional as organizaçôes de financiamento à pesquisa relacionadas às doenças infecciosas, disponibilizando informaçôes relativas aos recursos e editais existentes em diversos países/ organizaçóes - não há informaçóes disponíveis sobre o Brasil.

Outro debate cuja relevância deve crescer está relacionado ao patenteamento das tecnologias - novas e já existentes - de medicamentos, produtos e equipamentos médicos a serem utilizados para lidar com a pandemia. Licenças compulsórias podem ser um caminho adotado por diversos países. ${ }^{10} \mathrm{~A}$ maioria das jurisdiçôes possui leis de licenciamento compulsório ou de uso governamental em vigor, que podem ser usadas em caso de necessidade pública. Entretanto, até o momento, a emissão de tais licenças para medicamentos patenteados estava principalmente associada a países como Índia, Indonésia, Brasil, Chile, África do Sul e Malásia. Mas, dada a natureza sem precedentes da crise médica e econômica relacionada à Covid-19, essas medidas podem se tornar mais atraentes em jurisdiçôes onde essa prática tem sido menos comum.

Todos os Estados-membros da Convenção Europeia de Patentes possuem leis nacionais que permitem que seus governos licenciem ou usem patentes obrigatoriamente no interesse da saúde pública, desde que seja paga uma compensação razoável. Até os Estados Unidos, que criticam o licenciamento compulsório, têm leis sobre o estatuto que permitem medidas similares. ${ }^{11}$

9. Instituição que coordena em nível europeu as ações relacionadas ao tema. Disponível em: <https://www.ecdc.europa.eu/en>. 
No Canadá, em resposta à pandemia atual, os legisladores aprovaram um projeto de lei (PL) para acelerar o processo de emissão de licenças compulsórias referentes a produtos médicos. A lei canadense já permite que o governo emita uma licença compulsória, mas o projeto aceleraria o processo, permitindo que o país se movesse mais rápido para garantir uma licença no caso de uma crise de saúde pública. No momento, a medida parece projetada para garantir o acesso a equipamentos de proteção individual em situaçóes em que ocorram erros de preços ou em que uma empresa seja incapaz de lidar com pedidos. Nesses casos, o governo poderia emitir uma licença para outra empresa fabricar os produtos. ${ }^{12}$

O governo alemão também pretende aprovar emendas à Lei Alemã de Prevenção e Controle de Doenças Infecciosas em Humanos, o que também pode impactar em patentes. ${ }^{13}$ Em uma situação epidêmica, o Ministério Federal da Saúde seria autorizado a ordenar que uma invençáo relacionada aos produtos necessários seja usada no interesse do bem-estar público ou no interesse da segurança nacional. Ainda, a Assembleia Nacional do Equador foi convidada por um de seus comitês a conceder licenças compulsórias sobre direitos relacionados ao novo coronavírus, enquanto a Câmara dos Deputados do Chile aprovou uma resolução com o mesmo efeito. ${ }^{14}$

Em síntese, ainda existe a possibilidade de que ocorram disputas judiciais derivadas da propriedade intelectual dos produtos relacionados ao combate à epidemia. O resultado dessas disputas ainda é incerto. ${ }^{15}$

\section{CONSIDERAÇÕES FINAIS}

O enfrentamento de uma epidemia como essa requer, mais do que nunca, a opiniáo especializada e bem informada de cientistas e pesquisadores que conhecem e têm capacidade de pesquisa sobre a dinâmica da doença e de sua transmissão. Por ser uma doença nova, requer também que sejam produzidas as respostas necessárias e ainda inexistentes para o controle da epidemia e a mitigação de seus impactos na sociedade e, até mesmo, para calibrar as medidas adotadas, a fim de minimizar os impactos negativos na economia.

Isso demandaria, contudo, coordenação governamental e transparência nas informaçóes sobre a doença, dois elementos aparentemente ausentes na atuação do governo brasileiro até o momento. Existe pouquíssima informação sobre a situação da doença no Brasil: mais do que a evolução dos casos, dados epidemiológicos mais completos deveriam estar disponíveis.

A coordenação governamental para ampliar pesquisas na área seria crucial para melhor entender e preparar-se adequadamente para o que está por vir. Diversos países mobilizaram seus cientistas e pesquisadores e disponibilizaram linhas de suporte para novas pesquisas necessárias para fazer frente à epidemia. Cientistas e pesquisadores de universidades e instituiçóes de pesquisa no país deveriam estar sendo mais ouvidos e apoiados para produzir novos conhecimentos sobre o tema.

No que diz respeito ao tratamento e à prevenção, é importante salientar que a obtenção de uma vacina ou de um tratamento só será possível, no tempo demandado pela evolução da doença, graças ao investimento realizado e ao conhecimento acumulado em anos de pesquisa na área. O Brasil, a despeito da fragilidade de sua estrutura de pesquisa e da redução recente dos investimentos em C\&T, ainda vem se mostrando capaz de contribuir em momento táo grave quanto o atual. Deixar de dar prioridade a tais investimentos nesse momento por receio de não ser possível concorrer com outros países na vanguarda do desenvolvimento científico e tecnológico seria ignorar as evidências e colocar em risco a capacidade de resposta futura da ciência brasileira em área táo relevante.

12. Disponível em: <https://www.statnews.com/pharmalot/2020/03/25/canada-compulsory-license-coronavirus-covid19/>.

13. Disponível em: <http://patentblog.kluweriplaw.com/2020/03/24/german-government-plans-possibilities-to-limit-patents-in-view-of-corona-pandemic/>.

14. Disponível em: <https://www.iam-media.com/law-policy/covid-19-emergency-may-expose-compulsory-licensing-limits>.

15. Disponível em: <https://elpais.com/tecnologia/2020-03-20/impresion-3d-para-evitar-el-colapso-de-los-recursos-sanitarios-por-el-coronavirus.html>. 


\title{
COORDENAÇÃO GOVERNAMENTAL NA CRISE DA COVID-19: BREVE PROPOSTA DE AÇÃO'
}

\author{
Flávia Schmidt² \\ Janine $\mathrm{Mello}^{3}$ \\ Pedro Cavalcante ${ }^{4}$
}

\section{SINOPSE}

Os dados sobre os impactos da pandemia da Covid-19 sugerem que os governos ao redor do mundo não estavam preparados para uma crise com essas proporçôes. As implicaçóes sanitárias, sociais e econômicas exigem a ação dos Estados em diversos segmentos e evidenciam o quão essencial é uma coordenação governamental efetiva. Este texto apresenta uma sugestão de um arranjo institucional de coordenação governamental que pode contribuir para um melhor desempenho das açóes adotadas pelo governo brasileiro neste momento.

Palavras-chave: pandemia; coronavírus; Covid-19; coordenação governamental.

\section{INTRODUÇÃO}

Os dados mais recentes sobre os impactos da atual pandemia sugerem que os governos ao redor do mundo não estavam preparados para os impactos atuais e, especialmente, os futuros.

O gerenciamento de crises dessa magnitude é uma responsabilidade central dos governos, e uma responsabilidade difícil de cumprir (Boin et al., 2005; Boin e Hart, 2003), exigindo açóes em diversos segmentos. A crise atual desafia diversas áreas de políticas públicas no curto e médio prazo. O êxito das medidas adotadas, contudo, não é apenas contingente à efetividade das medidas per se, mas também à uma coordenação governamental efetiva.

Ao longo do processo, não importará apenas a real capacidade de entrega de resultados pelos governos, mas também a percepção dos cidadãos sobre a ação governamental (Christensen et al., 2016). Também é importante manter em vista que grandes crises podem soar como um "alarme da democracia", e muitas vezes resultar em uma crise para a própria democracia, posto que proteger seus cidadãos contra as consequências de ameaças deveria ser uma tarefa central do Estado, e espera-se que os governos sejam capazes de cumprir tal papel. Ao romper com essa premissa tácita e compartilhada, a legitimidade das instituiçóes públicas e a reputação dos líderes políticos restariam prejudicadas (Boin, 2019).

\footnotetext{
1. Uma versão mais completa deste trabalho foi publicada como nota técnica e como artigo do Boletim de Análises Político-Institucionais.

2. Técnica de planejamento e pesquisa na Diretora de Estudos e Políticas do Estado, das Instituições e da Democracia (Diest) do Ipea.

3. Especialista em políticas públicas e gestão governamental e coordenadora-geral da Diest/lpea.

4. Especialista em políticas públicas e gestão governamental na Diest/lpea.
} 


\section{AFINAL, COMO IDENTIFICAR UMA CRISE?}

$\mathrm{Na}$ atualidade, aceitar uma definição de crise seria rejeitar seu caráter inegável de wicked problem. Tendo como referência crises como o furacáo Katrina, o acidente nuclear em Fukushima e a crise econômica de 2008, Topper e Lagadec (2013) assinalaram algumas características das crises no século XXI: 5

- de larga escala para fora de escala;

- de complexas a "ilegíveis";

- de fortemente relacionadas a totalmente interdependentes;

- de alta velocidade a de forma instantânea; e

- de eventos locais a deslocamentos amplos e profundos.

Os autores denominam essas crises de "crises fractais". Boin (2019) reúne elementos análogos para caracterizar o que denominou como "crises transfronteiras" (transboundary crises), em emergência, como uma ameaça às sociedades modernas:

- múltiplos domínios, múltiplas manifestações: tais crises atingiriam vários países e/ou múltiplas áreas de política, gerando efeitos imbricados;

- incubação e escalada rápidas;

- difícil rastreabilidade;

- múltiplos atores, responsabilidades conflitantes: há incerteza sobre qual ator é responsável ou sobre quem tem a capacidade de executar determinadas tarefas; e

- ausência de soluçóes prontas.

Passíveis ou não de definição, crises testam a capacidade dos governos (Farazmand, 2009)e desafiam a credibilidade de seus líderes. A contraparte das crises seria o "gerenciamento de crise", entendido como os processos pelos quais uma organização - ou o próprio Estado - lida com uma crise antes, durante e depois da ocorrência.

\section{COORDENAÇÃO GOVERNAMENTAL: DETERMINANTES DE DESEMPENHO}

Diante da complexidade e do volume de responsabilidades decorrentes das crises, uma função é determinante para o desempenho governamental: a coordenação. Em linhas gerais, trata-se do alinhamento intencional de tarefas e esforços de atores e organizações para a superação da crise. Uma coordenação efetiva é ainda mais desafiadora em contextos democráticos, pelo respeito às regras do Estado de direito, pela cooperação entre atores internos e externos ao governo e pelo alto nível de transparência e accountability das decisóes, medidas e resultados. No caso brasileiro, particularidades institucionais - como o multipartidarismo, o federalismo, a autonomia do sistema de controle e a participação da sociedade na construção de políticas públicas - aumentam as dificuldades de coordenação. Como agravante, crises emergenciais como a da Covid-19 possuem características de wicked problems, ou seja, problemas ambíguos, dinâmicos, com baixo nível de informaçóes confiáveis, consequências intangíveis e que demandam soluções difíceis e interdependentes.

Como estratégia de construção de capacidades de coordenação que lidem com esse contexto, as naçóes vêm cada vez mais optando por fortalecer seus núcleos de governo $(\mathrm{NdG})$. Esse arranjo enfrenta dificuldades de

5. À época da publicação, Topper e Lagadec afirmaram que nenhuma crise ainda havia apresentado simultaneamente todos esses elementos. 0 ano de 2020 e a pandemia do novo coronavírus vieram contemplar o panorama completo descrito pelos autores. 
coordenação de caráter vertical (dentro do governo federal) e horizontal (demais poderes, entes subnacionais, sociedade e setor privado). Naturalmente, não existe modelo perfeito de coordenaçáo do $\mathrm{NdG}$, que precisa ser dinâmico e adaptado ao ambiente político e administrativo, bem como às particularidades da crise em questão. Todavia, algumas diretrizes (Lægreid et al., 2016; Banco Mundial, 2018; Cavalcante e Gomide, 2019) podem ser elencadas:

- independentemente da localização do $\mathrm{NdG}$, o fundamental é que o principal responsável tenha apoio permanente e qualidade de liderança (tecnicamente capacitado, experiência política e empoderado pelo chefe do Executivo);

- é crucial para obtenção de melhores resultados a utilização de instrumentos de coordenação flexíveis e adaptáveis;

- é preferível basear os instrumentos de coordenação não apenas em um mecanismo de governança, mas também na combinação dos três: autoridade hierárquica, cooperaçáo em redes e uso de incentivos;

- investir no gerenciamento estratégico das medidas institucionais, dos recursos, dos compromissos e suportes políticos contínuos, bem como das metas estabelecidas e dos resultados alcançados; e

- a comunicação e a gestão do conhecimento, combinadas com a avaliação e o monitoramento de obstáculos, medidas para resolvê-los, recursos e metas, são elos essenciais para accountability. Esse é cada vez mais complexo em coordenação de caráter horizontal e multinível, mas essencial para a contínua legitimidade e apoio às açóes.

\section{ATUAÇÃO DO ESTADO EM SITUAÇÕES DE CRISE: BREVE PROPOSTA DE AÇÃO}

Inúmeros países já enfrentaram calamidades diversas. O Brasil, por exemplo, já enfrentou crises energéticas (como em 2001), períodos prolongados de estiagem na região do semiárido (em 2013-2014) e outras crises sanitárias, como a epidemia de zika ocorrida em 2015-2016. Obviamente, o cenário atual se distingue enormemente das situaçóes mencionadas. Entretanto, a experiência dos casos anteriores servem como aprendizado para orientar a atuação governamental neste momento.

Não há manual padronizado sobre como proceder. Contudo, inúmeros trabalhos demonstram que experiências de outros países ou de outras situaçóes vivenciadas pelo próprio Brasil podem contribuir para o delineamento de diretrizes mínimas que evitem açôes fragmentadas, até mesmo em direções equivocadas. Nesse sentido, é crucial que as seguintes diretrizes orientem a coordenação da ação dentro e fora da esfera governamental:

- definição de instância de gestão legitimada e validada por todos os envolvidos no enfrentamento da crise;

- definição clara de papéis e competências;

- definição de fluxos e protocolos de ação;

- estabelecimento de instâncias de mediação e resolução de conflitos;

- criação de mecanismos de monitoramento, avaliação e feedback das açóes em curso; e

- utilização de instrumentos de transparência e prestação de contas na sociedade.

$\mathrm{Na}$ esteira dessas diretrizes, a primeira e mais usual medida tomada pelos governos em situaçóes de crise é o estabelecimento de comitês de crise, gabinetes de crise, comitês emergenciais, entre outras denominaçóes. No Brasil, esta instância é materializada pelo Comitê de Crise para Supervisão e Monitoramento dos Impactos 
da Covid-19, ${ }^{6}$ que conta com a participação de representantes de 27 entidades, como ministérios, empresas públicas e agências reguladoras.

A simples formalização de uma instância de coordenação em situações de crise não garante o sucesso no enfrentamento dos impactos observados nos momentos que antecedem a situação de emergência, em seu auge e no decorrer e mesmo no período pós-crise. De maneira geral, o momento de criação dessas instâncias é crucial. Há uma linha tênue e um difícil equilíbrio entre a antecipação dos riscos, as açóes preventivas e a criação de instâncias dessa natureza quando a crise está instaurada e seus efeitos já são sentidos pela populaçáo.

A despeito disso, após a constituição da instância responsável para enfrentamento da crise da Covid-19, é importante que a atuação coordenada da estrutura governamental tenha condiçóes de abarcar três grandes frentes de ação, descritas nas seçôes a seguir.

\subsection{Primeira frente: articulação político-institucional entre diferentes setores governamentais e não governamentais}

É de extrema relevância que, além de reuniōes periódicas, haja a definição de interlocutores responsáveis por dialogar e manter informados os diferentes atores envolvidos em relação às estratégias a serem adotadas, medidas em discussão e aquelas já colocadas em curso, assim como esforços de alinhamento de discursos e narrativas em setores como:

- setores econômicos de maior impacto;

- Unidades da Federação, priorizando aquelas com maior incidência da pandemia e/ou com maior vulnerabilidade;

- poderes Legislativo e Judiciário;

- países e organizaçóes internacionais; e

- terceiro setor e organizaçóes da sociedade civil com grande capacidade de mobilização social.

\subsection{Segunda frente: elaboração de uma estratégia nacional de enfrentamento da pandemia que contemple medidas emergenciais que dialoguem com esforços de outros entes federados, os demais poderes, além de setores empresariais e a própria sociedade civil}

Para ilustração, uma estratégia nacional de enfrentamento e contenção da Covid-19 poderia ser estruturada nos seguintes eixos:

- eixo 1: plano epidemiológico-sanitário;

- eixo 2: mitigação de impactos econômicos;

- eixo 3: fortalecimento da rede de proteção social;

- eixo 4: medidas de proteção ao trabalho, emprego e geração de renda; e

- eixo 5: pacote de medidas de apoio aos estados e municípios mais afetados.

6. Estabelecido pelo Decreto nำ 10.277, de 16 de março de 2020, sob a coordenação da Subchefia de Articulação e Monitoramento da Casa Civil da Presidência da República. 


\subsection{Terceira frente: estabelecimento de mecanismos de transparência das ações em andamento e comunicação com a sociedade}

- Definir porta-vozes específicos para tratar publicamente da pandemia. Não é necessário que a comunicação seja centralizada sob a figura de um representante; é possível que sejam apontados representantes em razão de expertise, competência institucional ou órgão ao qual pertence (ministros, servidores do alto escaláo do governo, governadores, prefeitos, especialistas em determinados temas, entre outros). No entanto, é crucial que haja coordenação e convergência entre falas e respostas dadas à sociedade como um todo para dirimir possíveis falhas de comunicação e evitar que orientações opostas ou contraditórias sejam repassadas.

- Definir periocidade e frequência com que a comunicação é feita. Isso agrega maior confiabilidade e previsibilidade à ação governamental diante das mudanças diárias vivenciadas nos momentos de auge da crise. É possível que sejam necessárias interaçóes diárias nos momentos de aguçamento da crise, que se tornem mais espaçadas no decorrer do tempo;

- Estabelecer o tipo de informaçáo (conteúdo e formato) e canais de comunicação que sejam de conhecimento público, em especial dos meios de comunicação, órgãos de pesquisa, think tanks, universidades e sociedade em geral.

- Responder com agilidade às novas situações que se manifestem, assumindo, inclusive, a assimetria e a incompletude das variáveis e evidências à disposição para a tomada de decisão ou fornecimento de maiores explicaçóes sobre determinados acontecimentos.

\section{CONSIDERAÇÕES GERAIS}

O enfrentamento de situaçóes de crise é um processo de curto, médio e longo prazo que demanda continuidade e manutenção de investimentos em políticas públicas transversais, combinados com estratégias de sustentação dos efeitos dessas medidas. É primordial garantir a combinação entre a agenda de políticas que visam ao impacto imediato e a resultados perceptíveis no curto prazo e aquelas estruturantes, direcionadas para romper as condiçôes de reprodução dos efeitos sociais e econômicos decorrentes da pandemia. Parte desses resultados não são necessariamente perceptíveis em períodos curtos, são mudanças cujos efeitos podem ser sentidos com intervalos maiores, por exemplo. Entretanto, o não investimento nessas açóes contribui para aprofundar e fortalecer as variáveis que influenciam a reprodução das vulnerabilidades que já marcam a sociedade brasileira em dimensões diversas.

Se a crise atual tem origem em uma pandemia, já está claro para o país que tanto a dimensão das ameaças dela decorrentes quanto as possíveis soluçôes para seu enfrentamento não terão origens ou resultados advindos de modo isolado da área de saúde. Para a busca de soluçóes, registra-se aqui uma proposta. Por fim, cabe lembrar que as crises podem ser também ameaças sérias para a própria democracia instituída, posto que a atuação do Estado será não apenas objetivamente mensurada pela restituição da normalidade à vida dos cidadáos como também será avaliada pela percepçáo da sociedade em relaçáo ao processo de gestáo da crise.

\section{REFERÊNCIAS}

BANCO MUNDIAL. Improving public sector performance: through innovation and inter-agency coordination. Global Report, summary, 2018.

BOIN, A. The transboundary crisis: why we are unprepared and the road ahead. Journal of Contingencies and Crisis Management, v. 27, n. 1, p. 94-9, 2019. 
BOIN, A.; HART, P. Public leadership in times of crisis: mission impossible? Public Administration Review, v. 63, n. 5 , p. 544-553, Sept./Oct. 2003.

CAVALCANTE, P.; GOMIDE, A. O presidente e seu núcleo de governo: a coordenação do Poder Executivo. Brasília: Ipea, 2019.

CHRISTENSEN, T. et al. (2016). Comparing coordination structures for crisis management in six countries. Public Administration, v. 94, n. 2, p. 316-332, 2016.

LÆGREID, P. et al. (Ed.). Organizing for coordination in the public sector: practices and lessons from 12 European countries. Springer, 2016.

TOPPER, B.; LAGADEC, P. Fractal crises: a new path for crisis theory and management. Journal of Contingencies and Crisis Management, v. 21, n. 1, p. 4-16, 2013.

\section{BIBLIOGRAFIA COMPLEMENTAR}

METCALFE, L. European policy management: future challenges and the role of the commission. Public Policy and Administration, v. 19, n. 3, p. 77-94, 2004.

PRESSMAN, J. L.; WILDAVSKY, A. Implementation: how great expectations in Washington are dashed in Oakland. Los Angeles: University of California Press, 1973. 


\section{EMPREGO SETORIAL E O ENFRENTAMENTO À COVID-19}

André Rauen ${ }^{1}$

Bianca Paiva ${ }^{2}$

Rafael Leão ${ }^{3}$

Bernardo Furtado ${ }^{4}$

\section{SINOPSE}

Considerando a necessidade de proteger o emprego e priorizar o apoio público, o objetivo deste trabalho é fornecer orientação à ação emergencial do Estado em nível setorial. O que este texto demonstrou foi que, entre aquelas atividades econômicas que mais empregam em todo o país, o comércio e os serviços de baixa complexidade seriam potencialmente os mais vulneráveis. Portanto, essas atividades poderiam ser priorizadas no apoio público.

Palavras-chave: pandemia; coronavírus; Covid-19; ajuda emergencial; atividades econômicas.

\section{INTRODUÇÃO}

Este trabalho tem por objetivo propor um indicador de identificação de atividades econômicas prioritárias para eventual apoio público governamental diante da atual pandemia da Covid-19 (Sars-CoV-2).

Considerando a necessidade de proteger o emprego e priorizar o apoio público, essa identificação setorial está baseada no pessoal ocupado (PO), disponibilizado na Relação Anual de Informaçôes Sociais (Rais) de 2018, último ano disponível. Assim, os dados referem-se apenas aos empregos formais no setor privado. Adicionalmente, utiliza-se como definição de atividades econômicas a desagregaçâo por grupos da Classificação Nacional das Atividades Econômicas (CNAE) versão 2.0.5

O objetivo final deste exercício empírico é o de fornecer alguma orientação à ação emergencial do Estado em todas as esferas governamentais, mesmo que ainda seja necessário algum refinamento com dados primários.

\section{MÉTODO}

O ranking de grupos econômicos prioritários (CNAE 2.0 a 3 dígitos) foi construído considerando quatro fatores, com o intuito de abranger aspectos relevantes no caso de ajuda econômica prioritária, otimizando eventuais recursos aportados:

\footnotetext{
1. Diretor na Diretoria de Estudos e Políticas Setoriais de Inovação e Infraestrutura (Diset) do Ipea.

2. Pesquisadora na Diset//pea.

3. Especialista em políticas públicas e gestão governamental na Diset/lpea e editor deste Radar.

4. Técnico de planejamento e pesquisa na Diset/lpea.

5. Disponível em: <https://bit.ly/3b9UPGZ>.
} 
- o PO do grupo perante o total da Rais;

- o coeficiente locacional do PO (Cruz et al., 2011); ${ }^{6}$

- o número de empregados acima de 60 anos no PO do grupo; ${ }^{7} \mathrm{e}$

- o número de empresas com PO menor que cinquenta empregados (uma medida de tamanho).

Essas escolhas têm por objetivo priorizar grupos econômicos de alta participação no emprego privado nacional, com alta dispersão espacial, com alta participação de idosos e empregados por empresas menores.

Para construir o ranking de grupos econômicos, diversos métodos foram testados - alguns, inclusive, com maior sofisticação. Contudo, os resultados foram sempre muito semelhantes, possivelmente porque o tamanho absoluto do PO influencia de forma direta quase todos os indicadores. Na tentativa de fornecer um indicador de fácil interpretação e rápida reprodução, optou-se por uma fórmula elaborada a partir da média simples dos números índices que compóem cada indicador individualmente, com ponderação três vezes maior para a participação setorial no PO total da Rais. Ou seja:

$$
I=\frac{(3 *(\% P O)+(\% \text { idosos })+(\% \text { pequenas })+(1-C L))}{6} .
$$

De fato, a participação no PO total é o principal elemento de definição do ranking, seja pela ponderação, seja pela presença do próprio PO nos outros indicadores individuais. Ou seja, trata-se de um ranking baseado, quase que totalmente, na participação do emprego setorial no qual os elementos adicionais apenas dão uma sintonia fina à análise. Como não se trata de uma análise de correlação, tal endogeneidade não apresenta qualquer efeito deletério à análise.

Com o ranking finalizado, foi feita uma indicação de atividades cujo funcionamento foi diretamente afetado pelos decretos de distanciamento social dos diferentes estados brasileiros. Como esses decretos variam e têm recebido constante atualização, optou-se por não incorporar tal informação na elaboração do ranking em si. Seria muito difícil afirmar que um determinado grupo econômico não possui impacto negativo mesmo tendo seu funcionamento autorizado. Nesse sentido, optou-se, apenas, por apontar os grupos afetados pela maioria dos decretos estaduais.

Adicionalmente, com o objetivo de ilustrar as implicaçôes do ranking proposto, foram também observadas as atividades profissionais - segundo a Classificação Brasileira de Ocupaçôes $(\mathrm{CBO})^{8}$ - com maior participação percentual dentro de cada atividade econômica.

6.

$E_{k i}=$ pessoal ocupado (emprego) no Grupo CNAE $k$ e Microrregião $i$.

$E_{k}=$ pessoal ocupado na Microrregião $i$.

$E_{k}=$ pessoal ocupado no Grupo CNAE $k$.

$E=$ pessoal ocupado total.

$$
C L_{k}=\frac{1}{2} \sum_{i}\left|\frac{E_{k i}}{E_{k}}-\frac{E_{i}}{E}\right| .
$$




\section{RESULTADOS}

A tabela 1 apresenta os vinte grupos econômicos prioritários com indicação da proibição ou não de fechamento, segundo os decretos de distanciamento social dos estados. Como era esperado, nenhum dos vinte primeiros é da manufatura. Tais grupos pertencem às atividades comerciais e de serviços, com especial destaque para o comércio varejista, restaurantes, serviços de baixa intensidade tecnológica e transporte de passageiros. Do ponto de vista da atividade profissional, os vendedores de comércio varejista são aqueles mais relevantes no conjunto das atividades aqui apresentadas, pois, dos vinte grupos de atividades econômicas listadas, eles aparecem em seis com o maior percentual diante de outras profissóes $\mathrm{O}$ que não significa dizer que estes profissionais serão os únicos ou mais afetados pela atual situação. Tal identificação serve apenas para ilustrar que as atividades econômicas exploradas pelas empresas têm estreita ligação com as atividades profissionais dos empregados, e isso precisa ser levado em consideração.

Mediante o exposto, conclui-se que as atividades de comércio varejista em geral, incluindo restaurantes e aqueles serviços de baixa complexidade, como serviços de mecânicos e de transporte de passageiros, são, entre os maiores empregadores brasileiros, aqueles mais vulneráveis perante a crise econômica devido à pandemia, de acordo com os critérios elencados. Portanto, essas atividades poderiam ser priorizadas no apoio público.

É evidente, contudo, que toda a economia brasileira será negativamente impactada pela pandemia provocada pela Covid-19, inclusive a manufatura. O que este texto demonstrou foi que, entre aquelas atividades econômicas que mais empregam em todo o país, o comércio e os serviços de baixa complexidade seriam potencialmente os mais vulneráveis. 


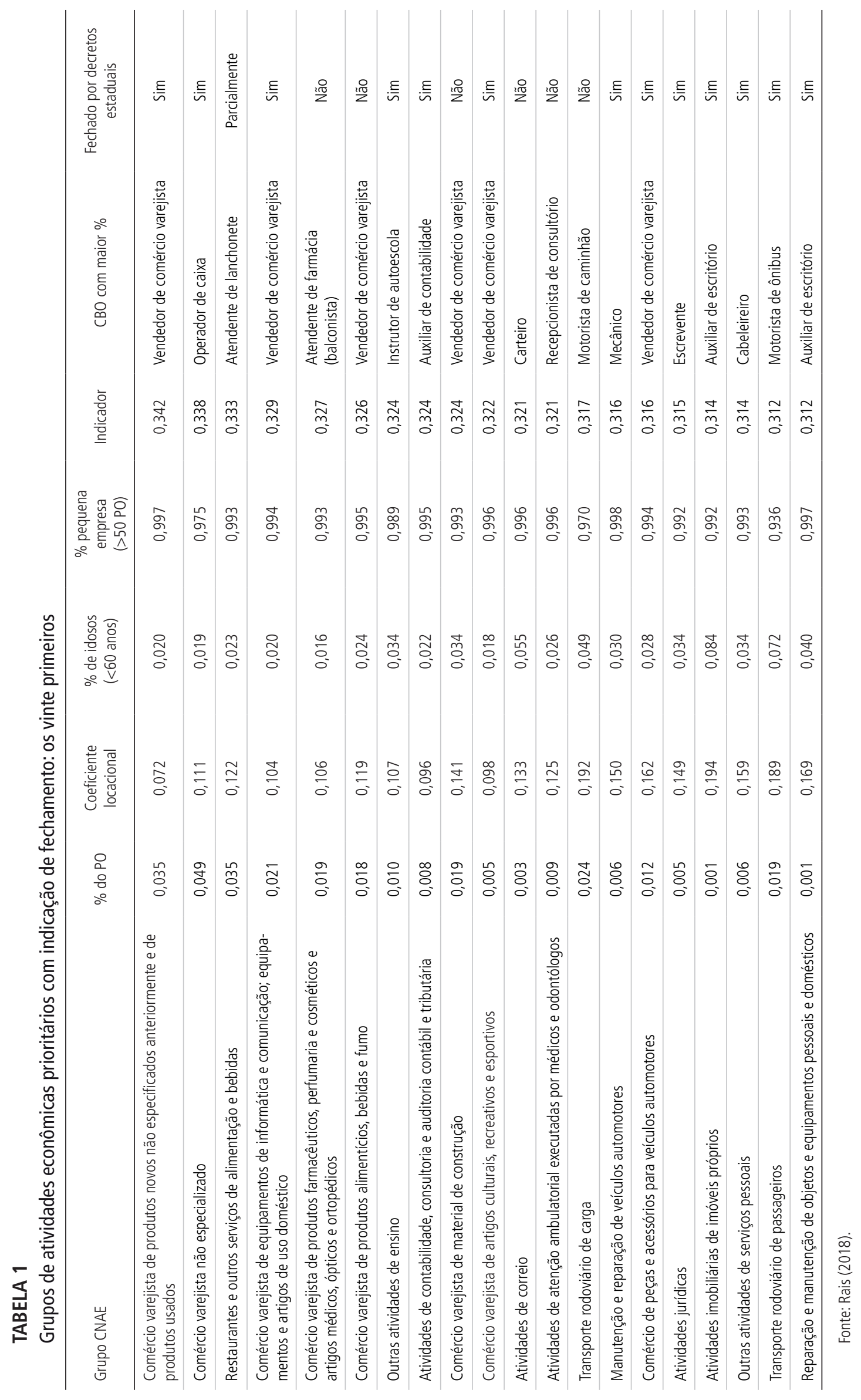




\section{REFERÊNCIAS}

CONHEÇA a faixa etária dos mortos por Covid-19 no Brasil, Itália, Espanha e EUA. Portal360, 3 abr. 2020. Disponível em: <https://bit.ly/2Rxu9Zd>. Acesso em: 14 abr. 2020.

CRUZ, B. et al. Economia regional e urbana: teorias e métodos com ênfase no Brasil. Brasília: Ipea, 2011. 
APÊNDICE A

TABELA A.1

Ranking de grupos CNAE 2.0, segundo elementos selecionados - Brasil (2018)

\begin{tabular}{|c|c|c|c|c|c|c|c|}
\hline Grupos & $\%$ do PO & Coeficiente locacional & $\%$ idosos & $\%$ tamanho & Indicador & CBO 2002 & $\%$ CBO no setor \\
\hline 478 & 0,0353 & 0,0721 & 0,0197 & 0,9965 & 0,3416 & 521110 & 0,4138 \\
\hline 471 & 0,0486 & 0,1110 & 0,0192 & 0,9745 & 0,3381 & 421125 & 0,1912 \\
\hline 475 & 0,0214 & 0,1044 & 0,0199 & 0,9942 & 0,3290 & 521110 & 0,3107 \\
\hline 477 & 0,0187 & 0,1058 & 0,0156 & 0,9932 & 0,3265 & 521130 & 0,1934 \\
\hline 859 & 0,0096 & 0,1068 & 0,0340 & 0,9887 & 0,3241 & 333105 & 0,1136 \\
\hline 692 & 0,0079 & 0,0961 & 0,0218 & 0,9946 & 0,3240 & 413110 & 0,2486 \\
\hline 474 & 0,0192 & 0,1410 & 0,0338 & 0,9934 & 0,3240 & 521110 & 0,2058 \\
\hline 476 & 0,0052 & 0,0984 & 0,0176 & 0,9956 & 0,3217 & 521110 & 0,3224 \\
\hline 452 & 0,0055 & 0,1500 & 0,0304 & 0,9979 & 0,3158 & 914405 & 0,1969 \\
\hline 453 & 0,0116 & 0,1616 & 0,0275 & 0,9938 & 0,3158 & 521110 & 0,1434 \\
\hline 691 & 0,0045 & 0,1486 & 0,0339 & 0,9915 & 0,3151 & 351405 & 0,1844 \\
\hline 681 & 0,0012 & 0,1942 & 0,0839 & 0,9918 & 0,3142 & 411005 & 0,1064 \\
\hline 960 & 0,0056 & 0,1593 & 0,0340 & 0,9928 & 0,3141 & 516110 & 0,0930 \\
\hline 492 & 0,0187 & 0,1892 & 0,0720 & 0,9361 & 0,3125 & 782410 & 0,3310 \\
\hline 952 & 0,0012 & 0,1689 & 0,0402 & 0,9974 & 0,3120 & 411005 & 0,0672 \\
\hline 949 & 0,0070 & 0,1930 & 0,0760 & 0,9676 & 0,3120 & 514320 & 0,1122 \\
\hline 931 & 0,0054 & 0,1808 & 0,0529 & 0,9809 & 0,3115 & 224120 & 0,1321 \\
\hline 412 & 0,0185 & 0,2126 & 0,0555 & 0,9429 & 0,3069 & 717020 & 0,2585 \\
\hline 750 & 0,0004 & 0,1733 & 0,0147 & 0,9978 & 0,3067 & 422105 & 0,1515 \\
\hline 468 & 0,0057 & 0,1899 & 0,0365 & 0,9685 & 0,3054 & 782510 & 0,0849 \\
\hline 943 & 0,0094 & 0,2073 & 0,0567 & 0,9546 & 0,3054 & 411005 & 0,1290 \\
\hline 772 & 0,0008 & 0,2099 & 0,0434 & 0,9950 & 0,3051 & 521110 & 0,1075 \\
\hline 851 & 0,0195 & 0,1683 & 0,0335 & 0,9066 & 0,3050 & 231210 & 0,0798 \\
\hline 829 & 0,0114 & 0,2144 & 0,0290 & 0,9750 & 0,3040 & 514320 & 0,0738 \\
\hline 181 & 0,0021 & 0,1995 & 0,0320 & 0,9818 & 0,3035 & 766315 & 0,0996 \\
\hline 451 & 0,0061 & 0,1521 & 0,0291 & 0,9242 & 0,3032 & 521110 & 0,2245 \\
\hline 773 & 0,0030 & 0,2062 & 0,0369 & 0,9796 & 0,3032 & 782510 & 0,0594 \\
\hline 467 & 0,0029 & 0,1920 & 0,0316 & 0,9685 & 0,3028 & 521110 & 0,0904 \\
\hline 682 & 0,0029 & 0,2171 & 0,0352 & 0,9865 & 0,3022 & 411005 & 0,2035 \\
\hline 951 & 0,0014 & 0,2013 & 0,0173 & 0,9918 & 0,3020 & 313220 & 0,1058 \\
\hline
\end{tabular}


(Continuação)

\begin{tabular}{|c|c|c|c|c|c|c|c|}
\hline Grupos & $\%$ do PO & Coeficiente locacional & $\%$ idosos & $\%$ tamanho & Indicador & CBO 2002 & $\%$ CBO no setor \\
\hline 562 & 0,0077 & 0,2428 & 0,0358 & 0,9789 & 0,2992 & 513505 & 0,2369 \\
\hline 461 & 0,0014 & 0,2311 & 0,0256 & 0,9934 & 0,2987 & 411005 & 0,1178 \\
\hline 942 & 0,0027 & 0,2898 & 0,0867 & 0,9750 & 0,2967 & 783210 & 0,2963 \\
\hline 865 & 0,0021 & 0,2543 & 0,0333 & 0,9947 & 0,2967 & 422105 & 0,1442 \\
\hline 433 & 0,0030 & 0,2535 & 0,0379 & 0,9854 & 0,2965 & 716610 & 0,1743 \\
\hline 109 & 0,0108 & 0,2440 & 0,0228 & 0,9665 & 0,2963 & 784205 & 0,1636 \\
\hline 662 & 0,0017 & 0,2426 & 0,0199 & 0,9935 & 0,2960 & 411005 & 0,2212 \\
\hline 331 & 0,0038 & 0,2548 & 0,0361 & 0,9813 & 0,2957 & 911305 & 0,0632 \\
\hline 941 & 0,0014 & 0,2919 & 0,0874 & 0,9718 & 0,2953 & 411010 & 0,1706 \\
\hline 464 & 0,0095 & 0,2468 & 0,0206 & 0,9689 & 0,2952 & 521110 & 0,0850 \\
\hline 432 & 0,0075 & 0,2683 & 0,0341 & 0,9781 & 0,2944 & 715615 & 0,0784 \\
\hline 611 & 0,0022 & 0,2336 & 0,0132 & 0,9767 & 0,2938 & 732130 & 0,0869 \\
\hline 791 & 0,0017 & 0,2590 & 0,0278 & 0,9882 & 0,2937 & 354815 & 0,1805 \\
\hline 932 & 0,0010 & 0,2661 & 0,0425 & 0,9818 & 0,2935 & 371410 & 0,0855 \\
\hline 821 & 0,0129 & 0,2786 & 0,0259 & 0,9748 & 0,2935 & 411010 & 0,0936 \\
\hline 871 & 0,0021 & 0,2479 & 0,0439 & 0,9574 & 0,2933 & 322205 & 0,1911 \\
\hline 551 & 0,0085 & 0,2784 & 0,0384 & 0,9712 & 0,2928 & 513315 & 0,2070 \\
\hline 823 & 0,0013 & 0,2728 & 0,0287 & 0,9905 & 0,2917 & 521115 & 0,0775 \\
\hline 411 & 0,0033 & 0,2878 & 0,0588 & 0,9664 & 0,2912 & 717020 & 0,2389 \\
\hline 582 & 0,0011 & 0,2739 & 0,0544 & 0,9614 & 0,2909 & 766315 & 0,0788 \\
\hline 601 & 0,0010 & 0,3247 & 0,0861 & 0,9809 & 0,2909 & 261715 & 0,2520 \\
\hline 233 & 0,0027 & 0,2863 & 0,0439 & 0,9781 & 0,2906 & 717020 & 0,0986 \\
\hline 742 & 0,0004 & 0,2718 & 0,0184 & 0,9944 & 0,2904 & 411010 & 0,1158 \\
\hline 522 & 0,0036 & 0,2908 & 0,0471 & 0,9751 & 0,2904 & 514110 & 0,2065 \\
\hline 771 & 0,0014 & 0,2867 & 0,0487 & 0,9755 & 0,2903 & 782305 & 0,1280 \\
\hline 813 & 0,0007 & 0,3052 & 0,0593 & 0,9800 & 0,2894 & 622010 & 0,2476 \\
\hline 332 & 0,0010 & 0,2863 & 0,0303 & 0,9858 & 0,2888 & 774105 & 0,0870 \\
\hline 466 & 0,0032 & 0,2791 & 0,0302 & 0,9696 & 0,2884 & 521110 & 0,0932 \\
\hline 251 & 0,0029 & 0,2943 & 0,0350 & 0,9791 & 0,2881 & 724440 & 0,1500 \\
\hline 591 & 0,0007 & 0,2764 & 0,0232 & 0,9791 & 0,2880 & 421115 & 0,0917 \\
\hline 649 & 0,0006 & 0,2929 & 0,0379 & 0,9788 & 0,2876 & 524105 & 0,1747 \\
\hline 711 & 0,0056 & 0,3115 & 0,0490 & 0,9664 & 0,2868 & 717020 & 0,0753 \\
\hline 532 & 0,0012 & 0,2808 & 0,0220 & 0,9754 & 0,2867 & 519110 & 0,3945 \\
\hline 900 & 0,0004 & 0,3113 & 0,0350 & 0,9946 & 0,2866 & 411010 & 0,0728 \\
\hline 431 & 0,0021 & 0,3163 & 0,0611 & 0,9652 & 0,2860 & 782510 & 0,1312 \\
\hline 619 & 0,0015 & 0,2956 & 0,0144 & 0,9698 & 0,2822 & 732130 & 0,0860 \\
\hline 454 & 0,0020 & 0,3116 & 0,0116 & 0,9864 & 0,2821 & 521110 & 0,2294 \\
\hline 731 & 0,0026 & 0,3071 & 0,0132 & 0,9783 & 0,2821 & 521115 & 0,2085 \\
\hline 639 & 0,0003 & 0,3224 & 0,0260 & 0,9864 & 0,2818 & 411005 & 0,0968 \\
\hline 329 & 0,0014 & 0,3222 & 0,0286 & 0,9753 & 0,2810 & 784205 & 0,1891 \\
\hline 295 & 0,0003 & 0,3682 & 0,0575 & 0,9957 & 0,2810 & 914405 & 0,2642 \\
\hline 854 & 0,0009 & 0,3043 & 0,0413 & 0,9458 & 0,2809 & 232115 & 0,2240 \\
\hline 182 & 0,0006 & 0,3321 & 0,0249 & 0,9876 & 0,2804 & 766315 & 0,0643 \\
\hline 559 & 0,0005 & 0,3603 & 0,0433 & 0,9972 & 0,2803 & 513315 & 0,1667 \\
\hline
\end{tabular}


(Continuação)

\begin{tabular}{|c|c|c|c|c|c|c|c|}
\hline Grupos & $\%$ do PO & Coeficiente locacional & $\%$ idosos & \% tamanho & Indicador & CBO 2002 & $\%$ CBO no setor \\
\hline 429 & 0,0044 & 0,3200 & 0,0519 & 0,9291 & 0,2790 & 717020 & 0,1331 \\
\hline 381 & 0,0035 & 0,3192 & 0,0644 & 0,9164 & 0,2787 & 514205 & 0,2033 \\
\hline 873 & 0,0007 & 0,3175 & 0,0618 & 0,9216 & 0,2780 & 514320 & 0,0665 \\
\hline 469 & 0,0043 & 0,2905 & 0,0207 & 0,9223 & 0,2776 & 521125 & 0,0838 \\
\hline 861 & 0,0297 & 0,1757 & 0,0328 & 0,7145 & 0,2768 & 322205 & 0,2660 \\
\hline 253 & 0,0020 & 0,3669 & 0,0366 & 0,9762 & 0,2753 & 784205 & 0,1164 \\
\hline 970 & 0,0001 & 0,4110 & 0,0612 & 0,9935 & 0,2740 & 621005 & 0,1321 \\
\hline 880 & 0,0039 & 0,2621 & 0,0332 & 0,8604 & 0,2739 & 411005 & 0,1843 \\
\hline 620 & 0,0097 & 0,3654 & 0,0222 & 0,9439 & 0,2717 & 212405 & 0,1987 \\
\hline 712 & 0,0007 & 0,3582 & 0,0254 & 0,9556 & 0,2708 & 391205 & 0,1120 \\
\hline 383 & 0,0008 & 0,3892 & 0,0387 & 0,9710 & 0,2705 & 784205 & 0,1497 \\
\hline 799 & 0,0001 & 0,4036 & 0,0384 & 0,9878 & 0,2705 & 421120 & 0,1138 \\
\hline 421 & 0,0056 & 0,3064 & 0,0692 & 0,8424 & 0,2704 & 717020 & 0,1730 \\
\hline 360 & 0,0028 & 0,3866 & 0,1171 & 0,8830 & 0,2703 & 862205 & 0,1262 \\
\hline 812 & 0,0205 & 0,3432 & 0,0551 & 0,8481 & 0,2702 & 514320 & 0,4411 \\
\hline 325 & 0,0016 & 0,3561 & 0,0217 & 0,9506 & 0,2702 & 784205 & 0,1501 \\
\hline 646 & 0,0012 & 0,3953 & 0,0459 & 0,9651 & 0,2699 & 411010 & 0,1105 \\
\hline 81 & 0,0016 & 0,4397 & 0,0670 & 0,9540 & 0,2643 & 782510 & 0,1121 \\
\hline 141 & 0,0147 & 0,4474 & 0,0271 & 0,9604 & 0,2640 & 763210 & 0,2110 \\
\hline 592 & 0,0001 & 0,4654 & 0,0472 & 0,9959 & 0,2630 & 411005 & 0,0886 \\
\hline 702 & 0,0027 & 0,4252 & 0,0229 & 0,9690 & 0,2625 & 411010 & 0,1079 \\
\hline 869 & 0,0017 & 0,4376 & 0,0389 & 0,9685 & 0,2625 & 322205 & 0,1298 \\
\hline 222 & 0,0086 & 0,3598 & 0,0230 & 0,8849 & 0,2623 & 784205 & 0,2017 \\
\hline 310 & 0,0064 & 0,4470 & 0,0299 & 0,9643 & 0,2611 & 771105 & 0,1593 \\
\hline 152 & 0,0006 & 0,4576 & 0,0401 & 0,9769 & 0,2602 & 784205 & 0,1020 \\
\hline 422 & 0,0058 & 0,3350 & 0,0315 & 0,8462 & 0,2600 & 717020 & 0,0823 \\
\hline 852 & 0,0044 & 0,2229 & 0,0480 & 0,7175 & 0,2593 & 231210 & 0,0721 \\
\hline 465 & 0,0010 & 0,4190 & 0,0155 & 0,9564 & 0,2593 & 521110 & 0,0711 \\
\hline 351 & 0,0033 & 0,3630 & 0,0504 & 0,8560 & 0,2589 & 732120 & 0,1069 \\
\hline 221 & 0,0025 & 0,3929 & 0,0279 & 0,9103 & 0,2588 & 784205 & 0,1646 \\
\hline 282 & 0,0026 & 0,4198 & 0,0406 & 0,9216 & 0,2584 & 784205 & 0,0756 \\
\hline 661 & 0,0012 & 0,4304 & 0,0125 & 0,9476 & 0,2555 & 411010 & 0,0908 \\
\hline 853 & 0,0119 & 0,1971 & 0,0747 & 0,6117 & 0,2541 & 234520 & 0,0898 \\
\hline
\end{tabular}


(Continuação)

\begin{tabular}{|c|c|c|c|c|c|c|c|}
\hline Grupos & $\%$ do PO & Coeficiente locacional & $\%$ idosos & $\%$ tamanho & Indicador & CBO 2002 & $\%$ CBO no setor \\
\hline 525 & 0,0017 & 0,4336 & 0,0182 & 0,9351 & 0,2541 & 782220 & 0,0702 \\
\hline 370 & 0,0003 & 0,4739 & 0,0477 & 0,9492 & 0,2540 & 782510 & 0,1002 \\
\hline 721 & 0,0010 & 0,4732 & 0,1218 & 0,8647 & 0,2527 & 411010 & 0,0736 \\
\hline 872 & 0,0004 & 0,4751 & 0,0453 & 0,9430 & 0,2524 & 322205 & 0,1452 \\
\hline 207 & 0,0008 & 0,4238 & 0,0286 & 0,9055 & 0,2521 & 811130 & 0,1012 \\
\hline 323 & 0,0001 & 0,5101 & 0,0357 & 0,9822 & 0,2514 & 784205 & 0,1440 \\
\hline 286 & 0,0019 & 0,4709 & 0,0441 & 0,9255 & 0,2507 & 724315 & 0,0655 \\
\hline 174 & 0,0013 & 0,4400 & 0,0216 & 0,9175 & 0,2505 & 784205 & 0,1674 \\
\hline 774 & 0,0003 & 0,4713 & 0,0133 & 0,9595 & 0,2504 & 411010 & 0,1038 \\
\hline 862 & 0,0003 & 0,4567 & 0,0356 & 0,9173 & 0,2495 & 515135 & 0,1952 \\
\hline 642 & 0,0139 & 0,1757 & 0,0229 & 0,6013 & 0,2484 & 413225 & 0,2600 \\
\hline 231 & 0,0011 & 0,4068 & 0,0215 & 0,8693 & 0,2479 & 784205 & 0,1579 \\
\hline 910 & 0,0001 & 0,5198 & 0,0488 & 0,9537 & 0,2472 & 352205 & 0,1821 \\
\hline 655 & 0,0026 & 0,2208 & 0,0206 & 0,6747 & 0,2471 & 411010 & 0,1862 \\
\hline 106 & 0,0039 & 0,4515 & 0,0293 & 0,8911 & 0,2468 & 784205 & 0,1640 \\
\hline 284 & 0,0004 & 0,5292 & 0,0441 & 0,9634 & 0,2466 & 721215 & 0,0800 \\
\hline 801 & 0,0151 & 0,3594 & 0,0252 & 0,7546 & 0,2443 & 517330 & 0,8567 \\
\hline 15 & 0,0140 & 0,5957 & 0,0581 & 0,9594 & 0,2440 & 621005 & 0,3173 \\
\hline 462 & 0,0021 & 0,5390 & 0,0303 & 0,9647 & 0,2437 & 411005 & 0,0832 \\
\hline 135 & 0,0030 & 0,5185 & 0,0308 & 0,9342 & 0,2426 & 784205 & 0,1107 \\
\hline 16 & 0,0037 & 0,5855 & 0,0572 & 0,9657 & 0,2414 & 621005 & 0,1801 \\
\hline 209 & 0,0016 & 0,4482 & 0,0329 & 0,8557 & 0,2409 & 784205 & 0,1144 \\
\hline 162 & 0,0027 & 0,5651 & 0,0398 & 0,9598 & 0,2404 & 784205 & 0,2475 \\
\hline 279 & 0,0007 & 0,4996 & 0,0256 & 0,9144 & 0,2404 & 784205 & 0,1382 \\
\hline 822 & 0,0123 & 0,4211 & 0,0055 & 0,8207 & 0,2403 & 422310 & 0,5316 \\
\hline 602 & 0,0014 & 0,3564 & 0,0436 & 0,7476 & 0,2398 & 373130 & 0,0929 \\
\hline 105 & 0,0032 & 0,5362 & 0,0228 & 0,9318 & 0,2380 & 841505 & 0,1726 \\
\hline 920 & 0,0000 & 0,6985 & 0,1293 & 0,9916 & 0,2371 & 421205 & 0,1262 \\
\hline 111 & 0,0014 & 0,5495 & 0,0252 & 0,9387 & 0,2364 & 813125 & 0,1661 \\
\hline 234 & 0,0036 & 0,5610 & 0,0368 & 0,9310 & 0,2363 & 828110 & 0,2068 \\
\hline 12 & 0,0013 & 0,6048 & 0,0417 & 0,9752 & 0,2360 & 621005 & 0,1912 \\
\hline 803 & 0,0000 & 0,6378 & 0,0500 & 1,0000 & 0,2354 & 411005 & 0,1440 \\
\hline 112 & 0,0018 & 0,4617 & 0,0234 & 0,8442 & 0,2352 & 784205 & 0,1237 \\
\hline 265 & 0,0005 & 0,5295 & 0,0282 & 0,9105 & 0,2351 & 784205 & 0,0629 \\
\hline 173 & 0,0017 & 0,5101 & 0,0257 & 0,8886 & 0,2349 & 784205 & 0,2033 \\
\hline 273 & 0,0013 & 0,5046 & 0,0257 & 0,8785 & 0,2339 & 784205 & 0,1066 \\
\hline 103 & 0,0014 & 0,5609 & 0,0259 & 0,9344 & 0,2339 & 784205 & 0,2405 \\
\hline 108 & 0,0005 & 0,5933 & 0,0387 & 0,9556 & 0,2338 & 784205 & 0,0975 \\
\hline 274 & 0,0003 & 0,5725 & 0,0345 & 0,9321 & 0,2325 & 784205 & 0,1603 \\
\hline 321 & 0,0005 & 0,6070 & 0,0240 & 0,9739 & 0,2321 & 751125 & 0,1894 \\
\hline 732 & 0,0002 & 0,5787 & 0,0184 & 0,9458 & 0,2310 & 424115 & 0,1257 \\
\hline 293 & 0,0011 & 0,6124 & 0,0294 & 0,9605 & 0,2301 & 724315 & 0,1382 \\
\hline 524 & 0,0012 & 0,5329 & 0,0289 & 0,8807 & 0,2300 & 783205 & 0,1578 \\
\hline 244 & 0,0011 & 0,5628 & 0,0301 & 0,9062 & 0,2295 & 784205 & 0,1480 \\
\hline
\end{tabular}


(Continuação)

\begin{tabular}{|c|c|c|c|c|c|c|c|}
\hline Grupos & $\%$ do PO & Coeficiente locacional & $\%$ idosos & $\%$ tamanho & Indicador & CBO 2002 & $\%$ CBO no setor \\
\hline 781 & 0,0025 & 0,5144 & 0,0506 & 0,8298 & 0,2289 & 514320 & 0,2019 \\
\hline 183 & 0,0000 & 0,6417 & 0,0283 & 0,9810 & 0,2280 & 212405 & 0,0637 \\
\hline 511 & 0,0016 & 0,4777 & 0,0254 & 0,8079 & 0,2267 & 511105 & 0,1937 \\
\hline 390 & 0,0000 & 0,5713 & 0,0213 & 0,9077 & 0,2263 & 514225 & 0,2284 \\
\hline 855 & 0,0011 & 0,6273 & 0,0601 & 0,9054 & 0,2236 & 411010 & 0,0970 \\
\hline 281 & 0,0014 & 0,5524 & 0,0289 & 0,8533 & 0,2224 & 784205 & 0,0553 \\
\hline 651 & 0,0013 & 0,5232 & 0,0145 & 0,8354 & 0,2217 & 411010 & 0,0787 \\
\hline 134 & 0,0010 & 0,6610 & 0,0315 & 0,9423 & 0,2193 & 761410 & 0,0684 \\
\hline 324 & 0,0003 & 0,6327 & 0,0264 & 0,9075 & 0,2170 & 784205 & 0,2530 \\
\hline 161 & 0,0017 & 0,7204 & 0,0478 & 0,9688 & 0,2169 & 784205 & 0,1916 \\
\hline 11 & 0,0114 & 0,7096 & 0,0494 & 0,9226 & 0,2161 & 621005 & 0,1596 \\
\hline 203 & 0,0003 & 0,5696 & 0,0337 & 0,8306 & 0,2159 & 784205 & 0,0789 \\
\hline 322 & 0,0000 & 0,7120 & 0,0528 & 0,9508 & 0,2153 & 784205 & 0,1555 \\
\hline 261 & 0,0008 & 0,6061 & 0,0150 & 0,8802 & 0,2153 & 731180 & 0,1520 \\
\hline 266 & 0,0001 & 0,6323 & 0,0220 & 0,8972 & 0,2146 & 784205 & 0,0914 \\
\hline 654 & 0,0003 & 0,5601 & 0,0501 & 0,7881 & 0,2132 & 411010 & 0,2068 \\
\hline 99 & 0,0001 & 0,7111 & 0,0540 & 0,9346 & 0,2130 & 782510 & 0,0710 \\
\hline 142 & 0,0007 & 0,7447 & 0,0301 & 0,9677 & 0,2092 & 784205 & 0,1277 \\
\hline 643 & 0,0005 & 0,4756 & 0,0307 & 0,6971 & 0,2090 & 253225 & 0,1135 \\
\hline 512 & 0,0000 & 0,6189 & 0,0637 & 0,8077 & 0,2088 & 215305 & 0,1234 \\
\hline 382 & 0,0009 & 0,6503 & 0,1049 & 0,7929 & 0,2083 & 514215 & 0,4354 \\
\hline 294 & 0,0070 & 0,5469 & 0,0173 & 0,7559 & 0,2079 & 784205 & 0,1531 \\
\hline 509 & 0,0002 & 0,7725 & 0,0699 & 0,9457 & 0,2073 & 782705 & 0,2222 \\
\hline 101 & 0,0133 & 0,6313 & 0,0196 & 0,8111 & 0,2065 & 784205 & 0,2119 \\
\hline 271 & 0,0008 & 0,6680 & 0,0179 & 0,8760 & 0,2047 & 784205 & 0,1166 \\
\hline 283 & 0,0020 & 0,6854 & 0,0299 & 0,8773 & 0,2046 & 724315 & 0,1046 \\
\hline 32 & 0,0003 & 0,7618 & 0,0247 & 0,9633 & 0,2045 & 631325 & 0,1234 \\
\hline 31 & 0,0002 & 0,8172 & 0,0943 & 0,9455 & 0,2039 & 631210 & 0,4184 \\
\hline 513 & 0,0000 & 0,9782 & 0,2011 & 1,0000 & 0,2038 & 411005 & 0,4857 \\
\hline 14 & 0,0005 & 0,7322 & 0,0250 & 0,9199 & 0,2024 & 622115 & 0,1444 \\
\hline 491 & 0,0019 & 0,5531 & 0,0640 & 0,6961 & 0,2021 & 342405 & 0,1213 \\
\hline 352 & 0,0001 & 0,5085 & 0,0415 & 0,6780 & 0,2019 & 252105 & 0,0874 \\
\hline 242 & 0,0021 & 0,6608 & 0,0147 & 0,8500 & 0,2017 & 911305 & 0,0992 \\
\hline
\end{tabular}


(Continuação)

\begin{tabular}{|c|c|c|c|c|c|c|c|}
\hline Grupos & $\%$ do PO & Coeficiente locacional & $\%$ idosos & $\%$ tamanho & Indicador & CBO 2002 & $\%$ CBO no setor \\
\hline 285 & 0,0007 & 0,6576 & 0,0232 & 0,8400 & 0,2013 & 724315 & 0,0664 \\
\hline 22 & 0,0002 & 0,8135 & 0,0413 & 0,9776 & 0,2010 & 632325 & 0,0886 \\
\hline 614 & 0,0001 & 0,6886 & 0,0135 & 0,8797 & 0,2008 & 411005 & 0,0726 \\
\hline 211 & 0,0001 & 0,6236 & 0,0235 & 0,7979 & 0,1997 & 515225 & 0,0742 \\
\hline 133 & 0,0007 & 0,6841 & 0,0288 & 0,8511 & 0,1996 & 761330 & 0,1054 \\
\hline 132 & 0,0012 & 0,6902 & 0,0347 & 0,8488 & 0,1995 & 761005 & 0,1238 \\
\hline 89 & 0,0006 & 0,7423 & 0,0477 & 0,8874 & 0,1991 & 784205 & 0,0597 \\
\hline 268 & 0,0000 & 0,8432 & 0,0361 & 1,0000 & 0,1988 & 519110 & 0,2434 \\
\hline 13 & 0,0078 & 0,7695 & 0,0540 & 0,8825 & 0,1984 & 621005 & 0,2310 \\
\hline 243 & 0,0003 & 0,6364 & 0,0270 & 0,7977 & 0,1982 & 784205 & 0,1232 \\
\hline 192 & 0,0008 & 0,6442 & 0,0499 & 0,7805 & 0,1981 & 811310 & 0,1633 \\
\hline 262 & 0,0009 & 0,6781 & 0,0089 & 0,8544 & 0,1980 & 731180 & 0,2618 \\
\hline 501 & 0,0002 & 0,7945 & 0,1341 & 0,8431 & 0,1972 & 782705 & 0,1123 \\
\hline 301 & 0,0006 & 0,7683 & 0,0589 & 0,8889 & 0,1969 & 724210 & 0,0876 \\
\hline 641 & 0,0000 & 0,8710 & 0,0415 & 1,0000 & 0,1951 & 252545 & 0,8122 \\
\hline 267 & 0,0000 & 0,7741 & 0,0244 & 0,9146 & 0,1942 & 731150 & 0,1199 \\
\hline 204 & 0,0001 & 0,7357 & 0,0364 & 0,8636 & 0,1941 & 761005 & 0,1375 \\
\hline 783 & 0,0046 & 0,4838 & 0,0476 & 0,5827 & 0,1934 & 514320 & 0,1378 \\
\hline 104 & 0,0009 & 0,6564 & 0,0327 & 0,7774 & 0,1927 & 862150 & 0,0888 \\
\hline 263 & 0,0004 & 0,7161 & 0,0169 & 0,8542 & 0,1927 & 731180 & 0,0884 \\
\hline 309 & 0,0006 & 0,7568 & 0,0163 & 0,8918 & 0,1922 & 725505 & 0,1241 \\
\hline 23 & 0,0009 & 0,8019 & 0,0330 & 0,9183 & 0,1920 & 632125 & 0,3066 \\
\hline 264 & 0,0003 & 0,7280 & 0,0158 & 0,8593 & 0,1913 & 731180 & 0,1199 \\
\hline 275 & 0,0013 & 0,6763 & 0,0145 & 0,8049 & 0,1911 & 731175 & 0,1653 \\
\hline 523 & 0,0013 & 0,7355 & 0,0579 & 0,8195 & 0,1909 & 411010 & 0,0805 \\
\hline 122 & 0,0002 & 0,8081 & 0,0510 & 0,8931 & 0,1894 & 842125 & 0,1270 \\
\hline 502 & 0,0003 & 0,8657 & 0,0840 & 0,9055 & 0,1875 & 782705 & 0,1202 \\
\hline 653 & 0,0000 & 0,7952 & 0,0342 & 0,8800 & 0,1865 & 351735 & 0,1492 \\
\hline 131 & 0,0011 & 0,6927 & 0,0375 & 0,7631 & 0,1852 & 761005 & 0,1462 \\
\hline 102 & 0,0005 & 0,7658 & 0,0371 & 0,8310 & 0,1840 & 841484 & 0,3310 \\
\hline 153 & 0,0073 & 0,8324 & 0,0140 & 0,8977 & 0,1835 & 764005 & 0,2922 \\
\hline 644 & 0,0000 & 0,8529 & 0,0256 & 0,9231 & 0,1826 & 411010 & 0,1640 \\
\hline 212 & 0,0026 & 0,5324 & 0,0165 & 0,5814 & 0,1789 & 354150 & 0,1103 \\
\hline 647 & 0,0000 & 0,9348 & 0,0000 & 1,0000 & 0,1775 & 111415 & 0,3681 \\
\hline 503 & 0,0005 & 0,8001 & 0,0744 & 0,7881 & 0,1773 & 782705 & 0,1715 \\
\hline 154 & 0,0006 & 0,8855 & 0,0206 & 0,9207 & 0,1763 & 764005 & 0,1413 \\
\hline 303 & 0,0001 & 0,7184 & 0,0393 & 0,7273 & 0,1748 & 724315 & 0,1302 \\
\hline 495 & 0,0000 & 0,9590 & 0,0687 & 0,9375 & 0,1745 & 421125 & 0,1163 \\
\hline 353 & 0,0000 & 0,7719 & 0,0340 & 0,7826 & 0,1741 & 862120 & 0,2582 \\
\hline 60 & 0,0006 & 0,8503 & 0,0377 & 0,7973 & 0,1644 & 811310 & 0,1523 \\
\hline 494 & 0,0001 & 0,6231 & 0,0498 & 0,5556 & 0,1638 & 811005 & 0,2442 \\
\hline 72 & 0,0009 & 0,8908 & 0,0223 & 0,8407 & 0,1625 & 711130 & 0,0875 \\
\hline 151 & 0,0009 & 0,7971 & 0,0385 & 0,7227 & 0,1611 & 762005 & 0,2043 \\
\hline 652 & 0,0002 & 0,6975 & 0,0137 & 0,6471 & 0,1606 & 142330 & 0,1332 \\
\hline
\end{tabular}


Radar | 62 | abr. 2020

(Continuação)

\begin{tabular}{|c|c|c|c|c|c|c|c|}
\hline Grupos & $\%$ do PO & Coeficiente locacional & $\%$ idosos & \% tamanho & Indicador & CBO 2002 & $\%$ CBO no setor \\
\hline 645 & 0,0000 & 0,6746 & 0,0382 & 0,5833 & 0,1578 & 411010 & 0,0884 \\
\hline 272 & 0,0003 & 0,8438 & 0,0162 & 0,7671 & 0,1567 & 784205 & 0,3481 \\
\hline 291 & 0,0023 & 0,6667 & 0,0058 & 0,5349 & 0,1468 & 725505 & 0,3180 \\
\hline 172 & 0,0012 & 0,7418 & 0,0277 & 0,5702 & 0,1433 & 784205 & 0,0989 \\
\hline 71 & 0,0013 & 0,8881 & 0,0129 & 0,6727 & 0,1336 & 715125 & 0,1652 \\
\hline 171 & 0,0005 & 0,8757 & 0,0280 & 0,6176 & 0,1286 & 642005 & 0,0611 \\
\hline 241 & 0,0005 & 0,8748 & 0,0400 & 0,5903 & 0,1262 & 821205 & 0,0892 \\
\hline 91 & 0,0006 & 0,8812 & 0,0220 & 0,6080 & 0,1251 & 711325 & 0,0889 \\
\hline 121 & 0,0003 & 0,9884 & 0,0701 & 0,5357 & 0,1030 & 842120 & 0,4139 \\
\hline 232 & 0,0004 & 0,7439 & 0,0313 & 0,3261 & 0,1024 & 911305 & 0,0977 \\
\hline 292 & 0,0006 & 0,7843 & 0,0128 & 0,3636 & 0,0990 & 725505 & 0,0994 \\
\hline 193 & 0,0031 & 0,8763 & 0,0362 & 0,3952 & 0,0941 & 622110 & 0,1485 \\
\hline
\end{tabular}

Elaboração dos autores.

Obs.: CNAE - Classificação Nacional das Atividades Econômicas; PO - pessoal ocupado; e CBO - Classificação Brasileira de Ocupações. 


\title{
POLÍTICAS DE DESENVOLVIMENTO PRODUTIVO, TECNOLÓGICO E DE INOVAÇÃO: A PERSPECTIVA DA SEGURANÇA NACIONAL
}

\author{
Rafael Leão' \\ Luis Felipe Giesteira
}

\section{SINOPSE}

O risco de a atual crise sanitária evoluir, no Brasil, para patamares dramáticos relaciona-se, em parte, à sua fragilidade tecnológica e produtiva. $\mathrm{O}$ aumento dessas fragilidades em diversos dos nossos segmentos econômicos compromete sobremaneira a capacidade do Brasil em responder a crises como a atual. O presente texto sugere que a construçáo de capacidade produtiva, tecnológica e inovadora orientadas por missóes e demandas de Estado aumentaria a capacidade do país em responder mais efetivamente a outras crises que possam nos acometer.

Palavras-chave: pandemia; coronavírus; Covid-19; política de desenvolvimento produtivo, tecnológico e de inovação; segurança nacional.

\section{INTRODUÇÃO}

O Brasil está enfrentando um dos maiores desafios de sua história recente. Nossa populaçáo, nossa economia e nossos sistemas de bem-estar seráo colocados à prova diante da pandemia da Covid-19.

Autoridades sanitárias têm relatado carência de testes, insumos e equipamentos para proteger os profissionais de saúde e atender a crescente população contaminada. Vinte e três aviōes americanos foram dirigidos à China para buscar toneladas desses produtos (EUA enviam..., 2020). Fabricantes chineses já informam ao mundo que a fila de espera para novos contratos vai até o final de junho. Na Europa, carregamentos de equipamentos hospitalares e medicamentos estão simplesmente sendo confiscados durante escalas no trânsito entre os países (Coronavírus..., 2020).

Em meio à crescente rivalidade entre as naçóes (Guerra mundial..., 2020), é urgente a perspectiva do acirramento da crise sanitária e humanitária no Brasil pela carência desses produtos - desde máscaras até respiradores (Guerra por máscaras..., 2020). O Sistema Único de Saúde (SUS), um dos maiores sistemas públicos de saúde do mundo, vê-se subitamente fragilizado porque o país năo conta com uma base produtiva e tecnológica suficientemente diversificada.

O risco de a atual crise evoluir para patamares dramáticos na verdade relaciona-se menos à qualidade do sistema de saúde do Brasil do que à sua fragilidade tecnológica e produtiva. $\mathrm{O}$ aumento dessas fragilidades em diversos dos nossos segmentos econômicos compromete sobremaneira a capacidade do Brasil em responder a crises como a atual. ${ }^{3}$

1. Especialista em políticas públicas e gestão governamental na Diretoria de Estudos e Políticas Setoriais de Inovação e Infraestrutura (Diset) do Ipea e editor deste Radar.

2. Especialista em políticas públicas e gestão governamental na Diretoria de Estudos e Relações Econômicas e Políticas Internacionais (Dinte) do Ipea.

3. Guilhoto e Morceiro (2019) destacam que o país passa por uma acelerada fragilização de suas cadeias produtivas - sem um correspondente aumento no esforço tecnológico e de inovação do restante do setor empresarial. 
O aumento das tensôes comerciais e diplomáticas que vem marcando as primeiras décadas do século XXI apresentam-se como um complicador adicional para aquelas naçôes que dispóe de frágeis capacidades tecnológicas e produtivas autônomas. A crise, hoje, coloca-se no campo sanitário, mas o contexto de fundo, que é a nossa fragilidade produtiva e tecnológica, será novamente o ponto de estrangulamento da capacidade de resposta do Estado brasileiro quando novas crises irromperem.

Em particular, não se pode descartar novas epidemias globais - a Covid-19 já é a quarta em vinte anos -, muito menos crises ambientais, climáticas e energéticas, por exemplo. Qualquer que seja a natureza de uma eventual e provável crise futura, novamente serão as competências produtivas e tecnológicas que farão a diferença entre sucumbir, resistir ou mesmo transformá-la em oportunidade.

Assim, o presente artigo resgata o debate sobre essas políticas públicas como instrumentos de segurança nacional (em sentido amplo, como exposto a seguir) e estabilidade institucional.

\section{AÇÃO DO ESTADO ORIENTADA POR MISSÕES}

A crise do coronavírus trouxe uma das questóes mais controversas para o centro do debate: os limites da ação do Estado na economia.

Como a revista The Economist destacou recentemente (Rich..., 2020), a atuação emergencial do Estado como garantidor do sistema econômico e fornecedor de ajuda financeira e material para imensos contingentes populacionais passou a ser defensável para a grande parte dos economistas - ainda que o custo fiscal das medidas já anunciadas seja no mínimo 50\% maior que o da crise de 2008.

Todavia, não se pode perder de vista que a ação emergencial do Estado no caso brasileiro está seriamente comprometida pela ausência de uma base produtiva e tecnológica que deveria ter sido garantida por políticas públicas de ao menos uma década atrás. Ao não contar com a possibilidade de importaçóes na quantidade necessária, o país corre o risco de desabastecimento de insumos médicos e hospitalares.

Alianças institucionais pautadas por um pensamento autônomo e estratégico entre setor produtivo e Estado estão - ou ao menos estiveram - no centro do domínio científico e tecnológico dos Estados Unidos, da Europa e de alguns países asiáticos - sobretudo e crescentemente da China. Essas alianças institucionais se traduzem em políticas de desenvolvimento produtivo, tecnológico e de inovação.

Partindo da visão estratégica originária e concentrada no Estado, a celebração dessa aliança se dá não de forma reativa, pelas dificuldades que o setor produtivo tem para se desenvolver, mas sim pela instrumentalização do setor produtivo, por orientaçâo estratégica do Estado, para equacionar desafios nacionais.

Esse paradigma, referido na literatura como mission oriented (Mazzucato, 2017), ou seja, política de desenvolvimento produtivo, tecnológica e de inovação orientada por objetivos estratégicos, tem como virtude a capacidade de orientar o debate sobre a necessidade de tal tipo de política pública por dois motivos fundamentais:

- esclarece-se o alinhamento de objetivos e a razão da ação coordenada: enfrentar e resolver um determinado desafio nacional; e

- mitigam-se as possibilidades de captura institucional dos mecanismos de apoio financeiro/econômico do Estado ao setor produtivo; isso ocorre pela inversão da orientação: não é o Estado que se vê acionado pelo setor empresarial, mas justamente o contrário.

Vale apontar que um ponto controverso em debates sobre políticas de desenvolvimento produtivo, tecnológica e de inovação é o da determinação de quais setores econômicos devem ser priorizados. É sem dúvida justificada a cautela. Entretanto, as missóes aqui referidas decorrem de atividades essenciais para o próprio funcionamento do 
Estado, ou de assuntos de grande repercussão para o conjunto da sociedade. Assim, são as próprias funções do Estado que condicionam a pauta de desafios a serem superados, e não a escolha de setores econômicos a serem priorizados.

\section{PAPEL DO ESTADO NA DEFINIÇÃO DAS AGENDAS}

Originalmente, a ideia de políticas mission oriented foi construída em contraposição à de políticas innovation oriented. Aqui, as denominaçôes são de pouca utilidade, haja vista que países democráticos, como os Estados Unidos e a França, inovam essencialmente a partir de grandes programas de longo prazo que trazem mais ou menos explicitamente missóes inscritas. O ponto essencial é que, em sistemas dominados por políticas do segundo tipo, a primazia em conduzir o papel do Estado nos sistemas de inovaçáo cabe à interação entre o setor produtivo e a academia através do sistema político. ${ }^{4}$

O modelo de política de inovação consagrado nos países da Organização para a Cooperação e Desenvolvimento Econômico (OCDE), e no qual o Brasil tem se espelhado nas últimas décadas, ${ }^{5}$ do tipo innovation oriented traz a hipótese de que interaçóes políticas abertas e transparentes resultam em benefícios para o conjunto da sociedade. Contudo, pode-se argumentar que nesse modelo o Estado participa de fato como um mero catalizador da interação entre o empresariado e a comunidade acadêmica, apenas ofertando instrumentos de apoio financeiro/econômico. Essa é a forma que tem sido adotada no Brasil.

No entanto, os sistemas de representação política tornam-se um veículo pelo qual as comunidades científicas e o sistema produtivo interferem recorrentemente na definição das agendas de pesquisa e na construção dos instrumentos públicos de apoio à pesquisa e inovaçáo. Nesse contexto, é elevada a possibilidade de os instrumentos do Estado serem manobrados em favor de grupos de interesse pelo fenômeno da captura institucional. Isso inviabiliza a consolidação de perspectivas de longo prazo, que são essenciais para políticas de inovação e tecnológica minimamente ambiciosas.

Em que pese a importância de um sistema que permita uma concertação de agendas de pesquisa e inovação entre empresas e academia para a criação de um fluxo de geração de valor no mercado, não se pode ignorar que a liderança estratégica do Estado é essencial para a geração de soluções tecnológicas e inovadoras para questôes de segurança nacional.

Em trabalho recente, Mark Zachary Taylor estabelece que, fundamentalmente, o ponto-chave é a própria suspensão da interferência política nas decisões de Estado. Em outras palavras: o que torna alguns países mais tecnologicamente potentes que outros é a capacidade de instituir políticas "de segurança nacional” - segurança lato sensu, abrangendo para além da defesa nacional, a energia, a alimentação e a saúde. Outros autores, como Laura Weiss (2014), Meredith Woo (1998) e Richard Samuels (1994), adotam posiçóes semelhantes ao investigar as políticas públicas que países asiáticos vêm implementando e que têm os conduzido ao posto de potências produtivas e tecnológicas.

Esses autores enfatizam que o desenvolvimento produtivo e tecnológico a partir de "razóes de Estado" (Bobbio, 1983) não é mera retórica. O jogo de interesses políticos é um dado da realidade, mesmo em países como a China de hoje ou a Coreia dos anos 1970 e 1980. Isso é um fato inescapável e relevante na definição de

4. Conforme Taylor (2016). A referência a Olson (1996) ajuda a elucidar o ceticismo de Taylor com a reiterada importância do design institucional para a efetividade das políticas de desenvolvimento tecnológico, abrigando um ponto comumente caro aos economistas neoclássicos, do risco de captura em políticas industriais de corte vertical. Observe-se que, sem deixar de concordar com Taylor, destacamos como aspecto tão ou mais importante a dificuldade de se planejar e executar políticas tecnológicas minimamente ousadas, que demandam prazos muito superiores à vigência de um governo ou legislatura.

5. Para entender melhor a experiência brasileira das últimas duas décadas, ver De Negri e Rauen (2018) e De Negri, Rauen e Squeff (2018). 
prioridades e na forma institucional concreta com que as missóes são desdobradas em qualquer sistema político de qualquer nação.

Contudo, em alguns países, a percepção é de que a segurança nacional é imperativa - novamente, segurança lato sensu - e isso traz para o Estado o protagonismo na definição daquilo que é crucial não apenas para sua preservação, mas também para o bem-estar da população a longo prazo.

Obviamente, não se trata aqui de propugnar, para o caso brasileiro, um retorno a modelos do passado que propunham a autarquização. Trata-se de observar que a rejeição completa à ideia de que o Estado possa orientar uma autonomia produtiva e tecnológica em setores estratégicos reduziu o dinamismo tecnológico do país, aumentando sua fragilidade econômica e institucional. Claramente, o que temos praticado no Brasil contrasta com o que realizaram os países do leste asiático.

\section{CONCLUSÃO}

A pandemia de Covid-19 pode representar o momento para reiniciarmos uma discussão sobre o papel de políticas de desenvolvimento produtivo, tecnológico e de inovação para a segurança do Estado brasileiro. O caso atual é notório: a fragilidade da base produtiva e tecnológica nacional coloca em risco a efetividade do nosso sistema de saúde. Ao que tudo indica, situaçóes semelhantes seriam encontradas, mutatis mutandis, em outros complexos produtivos de grande relevância para a segurança nacional.

Assim, torna-se necessário compreendermos que há ao menos um punhado de grandes políticas públicas para as quais é preciso garantir a autonomia tecnológica e produtiva necessárias a seu atendimento. Depender quase integralmente de cadeias globais de suprimento pode comprometer a capacidade de oferecer condiçôes mínimas à população, como ilustra o caso atual.

Embora esse texto não ofereça soluçóes para o problema dessa pandemia, sugere-se que a construção de capacidade produtiva, tecnológica e inovadora orientadas por missóes e demandas de Estado aumentaria a capacidade do país em responder mais efetivamente a outras crises que possam nos acometer - e cuja probabilidade vem se elevando continuamente antes mesmo da atual crise. ${ }^{6}$

Se boa parte da literatura que explica os reiterados sucessos asiáticos estiver correta, ganharemos não apenas em incrementar nossa segurança sanitária, mas também em dar peso e acelerar nosso claudicante progresso tecnológico.

\section{REFERÊNCIAS}

ALLEN, J. et al. How the World Will Look After the Coronavirus Pandemic. Foreignpolicy.com, 20 March 2020. Disponível em: <https://bit.ly/2Vb2m34>.

BOBBIO, N. et al. Razáo de Estado. Dicionário de política. Brasília: Editora da UnB, 1983.

CORONAVÍRUS: EUA são acusados de pirataria e desvio de equipamentos que iriam para Alemanha, França e Brasil. G1 mundo, 4 de abril de 2020. Disponível em: <https://glo.bo/2yVLMeB.

DE NEGRI, F.; RAUEN, A. Innovation policies in Brazil during the 2000s: the need for new paths. Brasília: Ipea, 2018.

DE NEGRI, F.; RAUEN, A.; SQUEFF, F. H. S. Ciência, inovação e produtividade: por uma nova geração de políticas públicas. In: DE NEGRI, J.; ARAÚJO, B.; BACELETTE, R. (Orgs.). Desafios da Naçáo: artigos de apoio. Brasília: Ipea, 2018. 
EUA ENVIAM avióes cargueiros e limpam estoque de equipamentos médicos da China. Poder 360, 1o de abril de 2020. Disponível em: <https://bit.ly/2V6Fqlp>.

GUERRA MUNDIAL por equipamentos contra vírus vai afetar as naçóes, diz militares. Estadáo, 6 de abril de 2020. Disponível em: $<$ https://bit.ly/3elRxmk

GUERRA POR MÁSCARAS e respiradores reforça importância da indústria nacional Folha de S.Paulo, 7 de abril de 2020. Disponível em: <https://bit.ly/34BO4eI>.

GUILHOTO, P. R.; MORCEIRO, P. Penetração dos insumos importados na indústria brasileira. São Paulo: IEDI, 2019. MAZZUCATO, M. Mission-oriented innovation policy: challenges and opportunities, UCL Institute for Innovation and Public Purpose (IIPP), 2017. (Working Paper Series, n. 1).

OLSON, M. A lógica da ação coletiva. São Paulo: Edusp, 1996.

RICH countries try radical economic policies to counter Covid-19. The Economist, March 26th Edition.

SAMUELS, R. Rich nation strong army: national security and the technological transformation of Japan. Cornell: Cornell University Press, 1994.

TAYLOR, M. Z. The politics of innovation: why some countries are better than others at science and technology. Oxford, 2016.

WEISS, L. America Inc.? Innovation and enterprise in the national security state. Cornell: Cornell University Press, 2014.

WOO-CUMMINGS, M. J-E. National Security and the Rise of the Developmental State in Korea and Taiwan. In: ROWEN, H.S. Behind East Asian Growth: the political and social foundations of prosperity. London: Routledge, 1998. 



\section{RESENHA DAS NOTAS TÉCNICAS EVITANDO A PANDEMIA DA POBREZA: POSSIBILIDADES PARA O PROGRAMA BOLSA FAMIILIA E PARA O CADASTRO ÚNICO EM RESPOSTA À COVID-19 E ESTIMATIVAS DE PÚBLICO ELEGÍVEL E CUSTOS DO BENEFÍCIO EMERGENCIAL CRIADO PELO PL No 9.236/2017}

Rafael Leão

Este texto é uma resenha de:

Paiva, L. H., ${ }^{2}$ Souza, P. H. G., ${ }^{3}$ Bartholo, L.; ${ }^{4}$ Soares, $S .{ }^{5}$ Evitando a Pandemia da Pobreza: possibilidades para o Programa Bolsa Familia e para o Cadastro Único em resposta à Covid-19. Brasilia: Ipea, 2020.

(Nota Técnica, n. 59). Disponivel em: <https://bit.ly/2Khefyd>.

Paiva, L. H.; Souza, P. H. G.; Bartholo, L.; Soares, S. Estimativas de Público Elegível e Custos do Benefício Emergencial Criado pelo PL no 9.236/2017. (Nota Técnica, n. 60). Disponivel em: <https://bit.ly/2RANIQ8>.

\section{SINOPSE}

Para subsidiar o governo federal no entendimento dos caminhos a serem tomados para enfrentar a crise social causada pela Covid-19, a Disoc publicou duas notas técnicas (no 59 e no 60 ) sugerindo possíveis ações a serem implementadas no curto prazo, com indicaçôes da relação custo-benefício entre as dificuldades institucionais e operacionais, o custo fiscal e os benefícios para a população. Esta resenha tem o mero objetivo de consolidar as principais análises e resultados desses esforços, permitindo que as mensagens de ambas as notas técnicas alcancem um público ainda maior.

Palavras-chave: pandemia; coronavírus; Covid-19; Bolsa Família; Cadastro Único; ajuda emergencial.

\section{INTRODUÇÃO}

Desde o início da crise da Covid-19, sabe-se que o país seria acometido por dois grandes choques: um de origem sanitária e outro de origem econômica. As medidas de isolamento social e de fechamento e interrupção de diversas atividades econômicas, necessárias para conter o avanço da epidemia em território brasileiro, colocaram enorme parcela da população economicamente ativa em risco de desemprego, desocupação, ou mesmo causaram perdas expressivas de rendimento monetário.

Os trabalhadores informais e as populaçóes tradicionalmente mais vulneráveis do país subitamente vislumbraram um cenário de dificuldades econômico-financeiras ainda maiores. ${ }^{6}$ Medidas de ajuda financeira

\footnotetext{
1. Especialista em políticas públicas e gestão governamental na Diretoria de Estudos e Políticas Setoriais de Inovação e Infraestrutura (Diset) do Ipea e editor deste Radar.

2. Especialista em políticas públicas e gestão governamental em exercício na Diretoria de Estudos e Políticas Sociais (Disoc) do Ipea.

3. Técnico de planejamento e pesquisa na Disoc/lpea.

4. Especialista em políticas públicas e gestão governamental em exercício na Disoc/lpea.

5. Técnico de planejamento e pesquisa na Disoc/lpea.

6. Disponível em: <https://glo.bo/3beNiae>.
} 
emergencial para essas populaçôes tornaram-se o assunto central no debate sobre as açóes do Estado brasileiro para conter as consequências socioeconômicas que se abaterão sobre a economia do país.

Para subsidiar o governo federal no entendimento dos possíveis caminhos a serem tomados, a Disoc publicou a Nota Técnica no 59 no dia 27 de março, sugerindo possíveis açóes a serem implementadas no curto prazo, com indicaçôes da relação custo-benefício entre as dificuldades institucionais e operacionais, o custo fiscal e os benefícios para a população.

Naquele mesmo momento, o Projeto de Lei (PL) no 9.236/2017 foi aprovado pela Câmara dos Deputados e se encaminhava para aprovação no Senado Federal. Esse PL alterou critérios de concessão do Benefício de Prestação Continuada (BPC) e instituiu auxílio emergencial aos trabalhadores informais, autônomos, microempreendedores individuais e desempregados. A Disoc, então, publicou, no dia $1^{\circ}$ de abril, a Nota Técnica no 60, que apresenta uma estimativa dos benefícios para a população e dos custos para o Estado da aprovação dessa medida.

Este texto tem o mero objetivo de consolidar as principais análises e resultados desses esforços, permitindo que as mensagens de ambas as notas técnicas alcancem um público ainda maior.

\section{A NOTA TÉCNICA № 59}

A primeira nota técnica debateu possíveis cenários e critérios concretos de intervenção, tendo como pontos de partida o Programa Bolsa Família (PBF) e o Cadastro Único para Programas Sociais (Cadastro Único):

a) zerar a fila do PBF e postergar os processos de averiguação e revisáo cadastral, de maneira a permitir que as famílias já cadastradas e as que estão na fila de espera já recebam o benefício de maneira imediata, além de evitar que as pessoas se dirijam aos centros de referência em assistência social (Cras), atendendo a condicionantes sanitárias de não aglomeração de pessoas;

b) reajustar a linha de elegibilidade e o valor dos benefícios do PBF, atualizando os valores pagos;

c) criar um benefício extraordinário por pelo menos seis meses para todas as familias do PBF, pelo agravamento da situação de vulnerabilidade social trazida pela pandemia; e

d) criar um benefício extraordinário por pelo menos seis meses para todas as famílias do Cadastro Único com renda familiar per capita de até meio salário mínimo. Essa proposta incluiria beneficiários e náo beneficiários do Bolsa Família.

As simulações foram feitas a partir da combinação das quatro propostas elencadas acima. Primeiramente, analisaram-se os impactos fiscais, os benefícios para a população, os desafios institucionais e operacionais da medida $a$; em seguida, esses critérios foram utilizados para se avaliar a simulação das combinaçóes possíveis entre a medida $a$ e três variaçóes possíveis da medida $b$; posteriormente, foi feita a avaliação da combinação da medida $a$ com as três variaçóes da medida $b$ e mais duas variaçóes possíveis da medida $c$.

No caso da medida $d$, sua análise foi acumulada apenas com as medidas a e $b$ porque na prática ela seria uma extensão da medida $c$, visto que o grupo de pessoas do PBF está incluído no universo de pessoas do Cadastro Único. Vale pontuar que todas as combinaçôes possíveis, com o número de pessoas e famílias beneficiadas, bem como os valores recebidos, também por pessoa e por família, estão devidamente descritos na Nota Técnica no ${ }^{5}$; o número de combinaçóes possíveis entre as quatro linhas de ação totaliza 72.

As análises e simulaçóes foram conduzidas dessa maneira para contemplar diversas linhas de ação que partissem de desafios institucionais e operacionais mais triviais, mas de alcance social mais limitado e reduzido impacto fiscal, até linhas de ação com maiores complexidades institucionais e operacionais, porém que se traduzissem em maiores benefícios à população potencialmente atingida - e maiores impactos fiscais, consequentemente. 
Longe de se descreverem todas as combinações - o que nem mesmo a própria nota técnica se propôs a fazer -, vale destacar alguns pontos. A linha de ação com praticamente nenhum desafio institucional, medida $a$, representaria um custo fiscal de apenas $\mathrm{R} \$ 2,24$ bilhóes no exercício fiscal de 2020, além dos atuais $\mathrm{R} \$ 23,2$ bilhões que custaria o PBF entre a publicação da nota (abril) e o mês de dezembro. O número de pessoas e famílias atendidas sairia dos atuais 42,7 milhóes de pessoas e 13,8 milhóes de famílias para 47,7 milhóes de pessoas e 15,5 milhões de famílias. O benefício médio por família permaneceria praticamente inalterado: de R \$ 188 para $\mathrm{R} \$$ 183. O desafio operacional estaria em garantir que aproximadamente 1,7 milhão de cartóes do PBF fossem emitidos e alcançassem as famílias da fila de espera em tempo recorde, pela urgência da crise.

No outro extremo estaria a combinação das medidas $a, b$ e $d$. Ou seja: zerar a fila do PBF com reajuste dos valores dos benefícios pagos (29\%, no exemplo dado aqui) e criar um benefício adicional por família de R $\$ 450$ por pelo menos seis meses para as famílias com renda per capita mensal de até meio salário mínimo. Essa é a recomendação de ação emergencial dos próprios autores.

Nesse caso, a medida geraria um custo fiscal adicional para 2020 de $\mathrm{R} \$ 68,6$ bilhóes, mas os benefícios sociais seriam largamente potencializados. O número de pessoas e famílias alcançadas seria de 63,6 milhôes e 21,1 milhóes, respectivamente, e o benefício médio por família sairia dos atuais R\$ 188 para R\$ 633 .

Ainda que o custo fiscal seja praticamente quadruplicado neste que seria o cenário mais generoso, os $\mathrm{R} \$ 91,9$ bilhóes que custariam toda a ação - que inclui os $\mathrm{R} \$ 23,2$ bilhóes que já seriam regularmente gastos no PBF entre abril e dezembro de 2020 - representariam apenas menos de 1,3\% do produto interno bruto (PIB), tendo 2019 como referência. Como boa parte dessa linha de ação seria temporária, o impacto fiscal adicional, em proporção do PIB em 2021, seria de apenas 0,2\% - fruto dos ajustes no PBF, que, esses sim, teriam efeitos duradouros.

\section{A NOTA TÉCNICA № 60}

Enquanto a Nota Técnica no 59 estava sendo elaborada e enviada para publicação, o Congresso Nacional aprovava o PL no 9.236/2017, que instituiu um auxílio emergencial de $\mathrm{R} \$ 600$ a ser pago durante três meses para trabalhadores que atenderem aos critérios a seguir.

I. Forem maiores de 18 anos.

II.Não tenham emprego formal.

III. Não sejam beneficiários de outros programas assistenciais ou previdenciários, com exceção exclusiva ao PBF.

IV.Tenham renda domiciliar per capita de até meio salário mínimo ou renda total de até três salários mínimos.

V. Tenham recebido rendimentos tributáveis de no máximo R\$ 28.559,70 em 2018.

VI. Exerçam atividade na condição de microempreendedor individual (MEI), ou sejam contribuintes individuais do Regime Geral de Previdência Social (RGPS), ou ainda sejam trabalhadores informais ou desempregados.

A equipe da Disoc, então, tentou estimar os impactos do PL do ponto de vista do benefício social e do custo fiscal. A estratégia estatística envolveu, basicamente, uma análise dos microdados da Pesquisa Nacional por Amostra de Domicílios (PNAD) Contínua de 2018, pois parte relevante do público potencialmente beneficiário não está inscrita no Cadastro Único. Aqui está, de fato, o grande desafio de efetividade dessa medida: alcançar pessoas virtualmente invisíveis aos cadastros oficiais do governo.

Criando cenários distintos de efetividade, a simulação dos impactos trabalhou com níveis distintos de alcance dessas populações que estão à margem do Cadastro Único. Foram três cenários: dois mais extremos (e também mais improváveis), um de alcance de $100 \%$, outro de alcance de $0 \%$ do público náo inscrito no Cadastro Único; e um intermediário, de alcance de $50 \%$ desse público. 
Com base nos critérios de elegibilidade elencados anteriormente e nas interpretaçóes cadastrais e estatísticas da PNAD Contínua, o trabalho encontrou um público-alvo elegível de 59,2 milhóes de pessoas. Destas, 81,7\% são mais facilmente identificáveis, pois estão inscritas no Cadastro Único. As demais 10,9 milhóes são pessoas que podem se enquadrar em uma de quatro categorias:

- MEIs ou contribuintes individuais;

- trabalhadores por conta própria;

- empregados informais; e

- pessoas sem ocupação.

As estimativas de número de pessoas e famílias beneficiadas, o benefício médio e o custo fiscal estão na tabela 1 .

TABELA 1

Número de pessoas e de famílias beneficiadas, benefício médio e custo fiscal

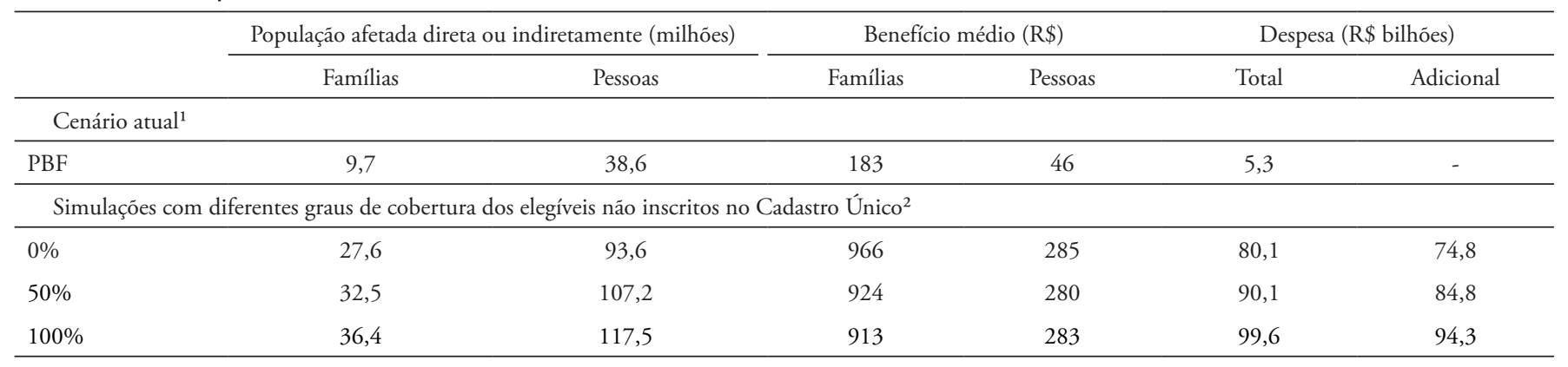

Fonte: Microdados da PNAD Contínua de 2018.

Notas: ${ }^{1}$ Os números do PBF estão subestimados em comparaçáo com os registros administrativos. Não fizemos nenhuma correçáo para isso. Em 2018, o número médio de famílias beneficiárias ficou próximo de 14 milhōes.

${ }^{2}$ Participação no Cadastro Único imputada para famílias beneficiárias do PBF, indivíduos beneficiários do BPC e famílias com renda mensal per capita de fontes formais menor ou igual a meio salário mínimo.

De qualquer maneira, vale aqui a notificação dessas estimativas para o cenário mais provável dos três apontados logo acima. Assim, no caso de o governo federal alcançar a metade das pessoas elegíveis que estão fora do Cadastro Único, o total de famílias e pessoas beneficiadas seria de 32,5 milhóes e 107,2 milhóes, respectivamente - considerando-se todas as pessoas diretamente beneficiadas ou que residem em lares onde há beneficiários. O benefício médio por família seria de R \$ 924 e o custo fiscal de R \$ 90,1 bilhóes no ano de 2020, o que representaria algo entre $1,0 \%$ e $1,3 \%$ do PIB de 2019.

\section{CONCLUSÃO}

A ajuda emergencial de R \$ 600 determinada pela aprovação do PL no 9.236/2017 figura como o principal instrumento de ação emergencial, do ponto de vista social, para ampla parcela da população brasileira pobre ou vulnerável à pobreza. O custo fiscal, segundo cálculos apresentados na Nota Técnica no 60 , seria modesto diante da calamidade pública que se avizinha nos próximos meses.

Não deixa de ser notável que essa ajuda emergencial analisada pela Nota Técnica no 60 se assemelhe bastante às propostas de ação que a mesma equipe da Disoc havia sugerido na Nota Técnica no 59 - objetivamente, as linhas de ação $c$ e $d$. As diferenças residem basicamente nos valores específicos dos benefícios e nos prazos de duração da ajuda emergencial - três meses no caso concreto, contra seis meses na proposta técnica. 

Ipea - Instituto de Pesquisa Econômica Aplicada

\section{Assessoria de Imprensa e Comunicação}

\section{EDITORIAL}

\section{Coordenação}

Reginaldo da Silva Domingos

\section{Assistente de Coordenação}

Rafael Augusto Ferreira Cardoso

\section{Supervisão}

Camilla de Miranda Mariath Gomes

Everson da Silva Moura

\section{Revisão}

Ana Clara Escórcio Xavier

Clícia Silveira Rodrigues

Idalina Barbara de Castro

Olavo Mesquita de Carvalho

Regina Marta de Aguiar

Amanda Ramos Marques (estagiária)

Hellen Pereira de Oliveira Fonseca (estagiária)

Ingrid Verena Sampaio Cerqueira Sodré (estagiária)

Isabella Silva Queiroz da Cunha (estagiária)

\section{Editoração}

Aeromilson Trajano de Mesquita

Cristiano Ferreira de Araújo

Danilo Leite de Macedo Tavares

Herllyson da Silva Souza

Jeovah Herculano Szervinsk Junior

Leonardo Hideki Higa

\section{Capa}

Leonardo Hideki Higa

\section{Imagens da Capa}

Banco Freepik (freepik.com)

\section{Projeto Gráfico}

Renato Rodrigues Bueno

The manuscripts in languages other than Portuguese published herein have not been proofread.

Livraria Ipea

SBS - Quadra 1 - Bloco J - Ed. BNDES, Térreo

70076-900 - Brasília - DF

Tel.: (61) 2026-5336

Correio eletrônico: livraria@ipea.gov.br 




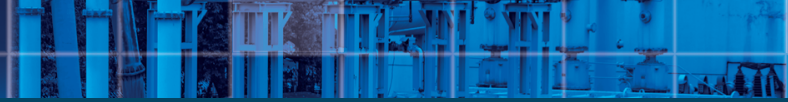

\section{Missão do Ipea}

Aprimorar as políticas públicas essenciais ao desenvolvimento brasileiro por meio da produção e disseminação de conhecimentos e da assessoria ao Estado nas suas decisões estratégicas.
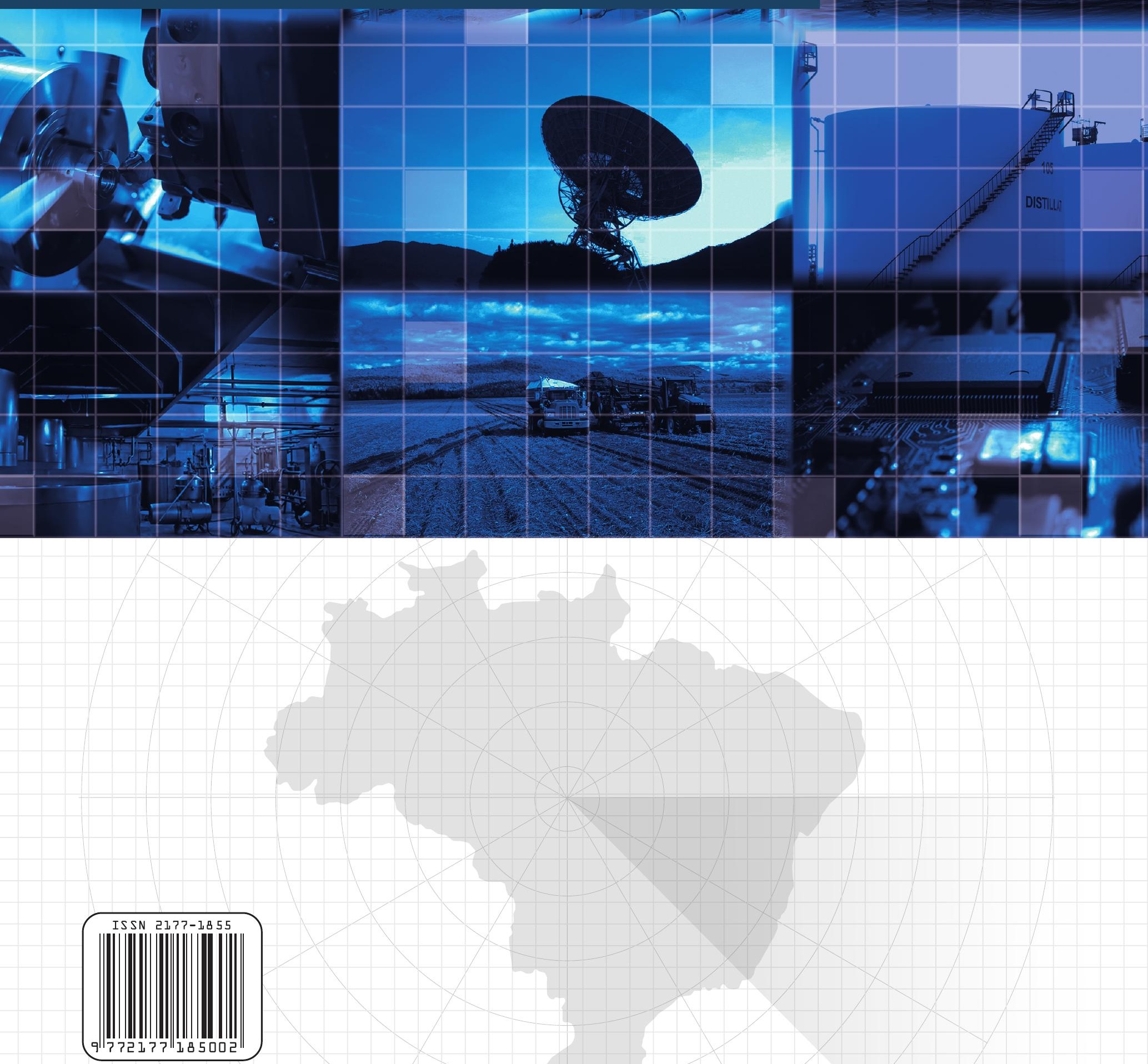